\title{
$C_{\text {. }} \mathbf{I} \cdot \mathbf{R}^{\circ} \mathbf{P} \cdot \mathrm{E} \cdot \mathrm{E}$ \\ Centre Interuniversitaire sur le Risque, les Politiques Économiques et l'Emploi
}

Cahier de recherche/Working Paper 12-19

\section{Model Implied Credit Spreads}

\author{
Gunnar Grass
}

Avril/April 2012

\author{
Grass: HEC Montréal, Canada and CIRPÉE \\ gunnar.grass@hec.ca
}

The paper benefited substantially from helpful comments by Yakov Amihud, Michael Brennan, Malte Brockmann, Jens Burchardt, Darrell Duffie, Pascal François, André Güttler, Andreas Hackethal, Jean Helwege, Paula Hill, Ulrich Hommel, Rainer Jankowitsch, Alexandre Jeanneret, Holger Kraft, Ehud Ronn, Tyler Shumway, Ilya Strebulaev, participants at the 2009 EFMA conference, the 2010 FMA conference, the 2011 MFA and DGF conferences, as well as seminar participants at HEC Montréal and the University of Pennsylvania. The author thanks Edward Altman for providing access to his bankruptcy database. Forough Ensandoust-Ghazvini and Manping Li provided valuable research assistance. Financial support from the German Research Foundation (DFG) and the Institut de Finance Mathématique de Montréal (IFM2) is gratefully acknowledged. 


\begin{abstract}
:
I propose a new measure of credit risk, model implied credit spreads (MICS), which can be extracted from any structural credit risk model in which debt values are a function of asset risk and the payout ratio. I implement MICS assuming a barrier option framework nesting the Merton (1974) model of capital structure. MICS are the increase in the payout to creditors necessary to offset the impact of an increase in asset variance on the option value of debt. Endogenizing asset payouts, my measure (i) predicts higher credit risk for safe firms and lower credit risk for firms with high volatility and leverage than a standard distance to default (DD) measure and (ii) clearly outperforms the DD measure when used to predict corporate default or to explain variations in credit spreads.
\end{abstract}

Keywords: Structural Credit Risk Models, Bankruptcy Prediction, Risk-Neutral Pricing

JEL Classification: G33, G13, G32 


\section{Introduction}

Recent research has reported deficiencies of structural models employed for quantifying credit risk. Eom et al. (2004) use five structural models for bond pricing and conclude that these tend to underestimate spreads of safe bonds while overstating credit spreads for bond issues of firms with high asset volatility and leverage. Bharath and Shumway (2008) construct a naïve bankruptcy predictor as an alternative to the classical Merton distance to default (DD) model which outperforms the original. They reason that "if the predictive power of our naïve probability is comparable to that of [the original model], then presumably a more carefully constructed probability that captures the same information should have superior power." Campbell et al. (2008) construct the current state-of-the-art statistical model for bankruptcy prediction using simple market and accounting variables. They demonstrate a substantial underperformance of Merton's DD model relative to theirs in terms of Pseudo- $R^{2} \mathrm{~s}$ and conclude that summarizing default estimates in a single predictor is not feasible.

Addressing these concerns about the ability of structural models to appropriately capture credit risk, I propose a new risk-neutral default measure based on model implied credit spreads. Model implied credit spreads are the increase in the payout to debtholders necessary to offset the impact of an increase in asset variance on the option values of debt and equity. I implement the approach using a barrier option framework which nests the simple Merton model of capital structure and compare properties and explanatory power of default probabilities estimated based on model implied credit spreads $\left(\pi_{M I C S}\right)$ to those estimated using a standard DD measure $\left(\pi_{D D-B}\right)$. I do not attempt to innovate on structural models itself but rather on the method used for extracting credit spreads 
and probabilities of default from existing models. The intuition underlying my approach can be applied to any structural model in which debt and equity are regarded as one or multiple options and valued as a function of asset risk and payout- ratio.

My approach has several advantages over a DD measure. First, $\pi_{M I C S}$ is higher than $\pi_{D D-B}$ for relatively safe firms and lower for firms with high leverage and volatility, as requested by Eom et al. (2004). Second, its estimation endogenizes asset payouts and thus incorporates the partial redistribution of asset value to creditors that occurs via interest payments made before debt maturity. Third, $\pi_{M I C S}$ clearly outperforms $\pi_{D D-B}$ when used for predicting corporate default in an empirical setting. ${ }^{1}$ The MICS approach thus is a promising alternative for estimating credit risk based on structural default models.

The paper is organized as follows. Section 2 lays the theoretical foundation of this study by presenting an option model of capital structure similar to those found in previous literature. Section 3 then explains the estimation of default probabilities. After establishing an extended DD measure nesting the standard Merton DD measure in Section 3.1, Section 3.2 introduces a new probability measure based on model implied credit spreads by first providing the underlying intuition (Section 3.2.1) and then deriving a numerical solution of the measure (Section 3.2.2). Section 4 presents results of a numerical sensitivity analysis, comparing properties of $\pi_{M I C S}$ and $\pi_{D D-B}$. Section 5 compares the measures' ability to predict corporate default in an empirical setting and includes various robustness checks. Section 6 concludes.

${ }^{1}$ The measure's outperformance when employed for explaining variations in credit default swap (CDS) rates. However, results are not yet included in this version of the article. 


\section{An Option Model of Capital Structure}

Debt and equity can be viewed as options on firm assets. In the simple Black-ScholesMerton (BSM) framework, shareholders own a call option on the value of the firm while debtholders hold a combination of a risk-free asset and a short put option on firm value. This is due to their characteristic payout profiles. Shareholders profit from positive firm developments but have a limited liability. In contrast, bondholders can lose their invested money but have limited upside potential. Given a positive development of the firm, they will simply receive the pre-agreed payoff at maturity.

Under an option model of capital structure with no taxes, firm value $V$ is the sum of equity and debt valued as contingent claims:

$$
V=\widehat{E}+\widehat{D}
$$

Assuming a simple BSM model, equity and debt values can be computed as

$$
\widehat{E}=C+\Delta_{E}
$$

and

$$
\begin{gathered}
\widehat{D}=D e^{-r T}-P+\Delta_{D}, \\
L G D=1-e^{\left(\mu-\delta_{V}\right) T} \times \frac{V}{D} \frac{N\left(-d_{1}(V, D)\right)}{N\left(-d_{2}(V, D)\right)}
\end{gathered}
$$

where $C$ is the value of a European call option on firm assets, $\Delta_{E}$ the present value of dividend payouts to shareholders, $D$ the face value of debt, $r$ the risk-free rate, $T$ the 
time to debt maturity, $-P$ the value of a short European put option on firm assets and $\Delta_{D}$ the present value of interest rate payments to debtholders.

As outlined by Brockman and Turtle (2003), the BSM framework ignores the path dependency of equity and debt. Specifically, it assumes the firm to continue operating until the expiration of debt contracts, no matter how low firm values are. In reality however, equity and debt can be knocked out whenever asset values fall below a legal barrier. Barrier option pricing allows to incorporate the path dependency of corporate securities.

In an extended framework,

$$
\begin{gathered}
\widehat{E}=C_{D O}+C_{D I}+\Delta_{E}, \\
\widehat{D}=D e^{-r T}-P_{D O}-P_{D I}+\Delta_{D},
\end{gathered}
$$

where $D O$ and $D I$ index down-and-out and down-and-in options which stop (start) existing once a predefined barrier $B$ has been hit and pay a rebate $\theta$ to the option holder if the barrier is (is not) breached before maturity, respectively. Equations 5-6 fully nest Equations 2-3 which represent the case of a zero barrier, as this barrier is never hit by the log-normal process underlying the pricing framework.

If firm assets are liquidated upon default, down-and-in options - which can be interpreted as options to continue firm operations after bankruptcy - are never exercised. Additionally assuming that payouts to claimholders are made only if the barrier has not yet been hit (as indicated by $\star$ ), Equations 5-6 reduce to

$$
\widehat{E}=C_{D O}+\Delta_{E}^{\star}
$$


and

$$
\widehat{D}=D e^{-r T}-P_{D O}+\Delta_{D}^{\star}
$$

Throughout this study, I use the pricing formulae derived by Black and Scholes (1973), Merton (1974), and Rubinstein and Reiner (1991). In the plain vanilla framework, the values of equity and debt as European call and put options $C$ and $P$ are functions of the firm value $V$, the face value of debt $D$, firm risk $\sigma_{V}$, the risk-free rate $r$, the time to debt maturity $T$, and the combined payout ratio to debt and equity holders $\delta_{V}$ :

$$
C=V e^{-\delta_{V} T} N\left(d_{1}(V, D)\right)-D e^{-r T} N\left(d_{1}(V, D)-\sigma_{V} \sqrt{T}\right),
$$

and

$$
P=D e^{-r T} N\left(-d_{1}(V, D)+\sigma_{V} \sqrt{T}\right)-V e^{-\delta_{V} T} N\left(-d_{1}(V, D)\right),
$$

where

$$
\begin{gathered}
d_{1}\left(X_{1}, X_{2}\right)=\ln \left(\frac{X_{1}}{X_{2}}\right) \frac{1}{\sigma_{V} \sqrt{T}}+\eta \sigma_{V} \sqrt{T} \\
\eta=.5+\frac{r-\delta_{V}}{\sigma_{V}^{2}}
\end{gathered}
$$

$N(\cdot)$ denotes the function describing the standard normal cumulative probability density, and

$$
\delta_{V}=\frac{E}{V} \delta_{E}+\frac{D}{V} \delta_{D}
$$

$E$ denotes the market value of equity, $\delta_{E}$ the dividend yield, and $\delta_{D}$ the debt payout ratio.

In the barrier pricing framework, I additionally incorporate information about bond- 
holders' expected loss given default in the put option's rebate $\theta$, as well as the bankruptcy barrier $B$, which is assumed to be equal to or below the face value of debt. The values of down-and-out call and put options equal

$$
C_{D O}=C-C_{D I^{*}}+\Theta
$$

and

$$
P_{D O}=P-P_{D I^{*}}+\Theta .
$$

$C_{D I^{*}}$ and $P_{D I^{*}}$ denote the values of a down-and-in call and put option with zero rebate equal to

$$
\begin{aligned}
C_{D I^{*}} & =V e^{-\delta_{V} T}\left(\frac{B}{V}\right)^{2 \eta} N\left(d_{1}\left(B^{2}, V D\right)\right) \\
& -D e^{-r T}\left(\frac{B}{V}\right)^{2 \eta-2} N\left(d_{1}\left(B^{2}, V D\right)-\sigma_{V} \sqrt{T}\right)
\end{aligned}
$$

and

$$
\begin{aligned}
P_{D I^{*}} & =V e^{-\delta_{V} T}\left[\left(\frac{B}{V}\right)^{2 \eta}\left(N\left(d_{1}\left(B^{2}, V D\right)\right)-N\left(d_{1}(B, V)\right)\right)-N\left(-d_{1}(V, B)\right)\right] \\
& -D e^{-r T}\left[( \frac { B } { V } ) ^ { 2 \eta - 2 } \left[N\left(d_{1}\left(B^{2}, V D\right)-\sigma_{V} \sqrt{T}\right)\right.\right. \\
& \left.\left.-N\left(d_{1}(B, V)-\sigma_{V} \sqrt{T}\right)\right]-N\left(-d_{1}(V, B)+\sigma_{V} \sqrt{T}\right)\right] .
\end{aligned}
$$

The present value of a down-and-out option's rebate is

$$
\Theta=\theta\left[\left(\frac{B}{V}\right)^{\eta-1+\xi} N\left(d_{2}\right)+\left(\frac{B}{V}\right)^{\eta-1-\xi} N\left(d_{2}-2 \xi \sigma_{V} \sqrt{T}\right)\right]
$$


with

$$
\xi=\frac{1}{\sigma_{V}^{2}} \sqrt{\left(r-\delta_{V}-.5 \sigma_{V}^{2}\right)^{2}+2 r \sigma_{V}^{2}}
$$

and

$$
d_{2}=\ln \left(\frac{B}{V}\right) \frac{1}{\sigma_{V} \sqrt{T}}+\xi \sigma_{V} \sqrt{T}
$$

When valuing debt and equity as barrier options, I set the call option's rebate $\theta_{E}$ to zero, as shareholders' claim is worthless in the case of bankruptcy. While counterintuitive at first, the put option's rebate equals debtholders' loss given default $(L G D)$ in dollar terms

$$
\theta_{D}=L G D \times D
$$

As debtholders are assumed to hold a short put, they have to pay the rebate in case the bankruptcy barrier is hit and at the same time continue to hold the risk-free asset. In sum, their claim thus reduces to the amount recovered in default.

\section{Estimating Probabilities of Default}

\subsection{Distance to Default Measures}

The previously described option model of capital structure assumes firm value to follow a a geometric Brownian Motion:

$$
\frac{d \mathrm{~V}}{\mathrm{~V}}=\left(\mu-\delta_{\mathrm{V}}\right) d t+\sigma_{\mathrm{V}} d \mathrm{~W},
$$

where $\mu-\delta_{V}$ denotes the process' drift rate and $d \mathrm{~W}$ is a standard Wiener process.

Based on this assumption, the probability of default can be calculated as the probabil- 
ity that firm value falls below a certain bankruptcy threshold at or before debt expiration. Under the simple BSM model, a firm's probability of default is the probability that firm value is below the face value of debt at expiration. It is thus a function of Merton's DD measure, defined as the number of standard deviations by which assets exceed liabilities:

$$
D D=\frac{\left(\ln \left(\frac{V}{D}\right)+\left(\mu-\delta_{V}-.5 \sigma_{V}^{2}\right) T\right)}{\sigma_{V} \sqrt{T}} .
$$

The probability of default is then defined as

$$
\pi_{D D}=N(-D D) .^{2}
$$

Accounting for the path dependency of corporate securities in the barrier option framework, I calculate the probability of default as

$$
\pi_{D D-B}=1-\left(1-\pi_{D D}\right)\left(1-\pi_{B}\right)
$$

where the probability of a premature option knockout $\pi_{B}$ equals $^{3}$

$$
\begin{aligned}
\pi_{B} & =N\left(\frac{\ln \left(\frac{B}{V}\right)-\left(\mu-\delta_{V}-.5 \sigma_{V}^{2}\right) T}{\sigma_{V} \sqrt{T}}\right) \\
& +e^{2\left(\mu-\delta_{V}-.5 \sigma_{V}^{2}\right) \ln \left(\frac{B}{V}\right) \frac{1}{\sigma_{V}^{2}}} \\
& {\left[1-N\left(\frac{-\ln \left(\frac{B}{V}\right)-\left(\mu-\delta_{V}-.5 \sigma_{V}^{2}\right) T}{\sigma_{V} \sqrt{T}}\right)\right] . }
\end{aligned}
$$

\footnotetext{
${ }^{2}$ For a thorough derivation, see Vassalou and Xing (2004), pp.836f.

${ }^{3}$ Compare Brockman and Turtle (2003). My DD measure differs from theirs in that (i) it uses the physical drift rate, (ii) it incorporates the payout ratio $\delta_{V}$, and (iii) it combines the probability of premature option knockout and the probability of default at maturity. In contrast to theirs, my DD measure therefore fully nests the plain vanilla Merton measure.
} 
Again, the plain vanilla framework is fully nested in the extended framework: Assuming $B=0, \pi_{B}=0$, which implies $\pi_{D D-B}=\pi_{D D}$.

\subsection{Model Implied Credit Spreads}

While the theoretical framework underlying DD-like default measures is intuitively appealing, their performance in empirical studies is unsatisfactory. ${ }^{4}$ In the following, I therefore introduce model implied credit spreads as an alternative way to derive default probabilities from any structural model in which debt is regarded as one or multiple options and valued as a function of asset risk and payout ratio.

\subsubsection{Intuition}

Suppose creditors can adjust the cost of debt instantaneously and at all points in time know the exact risk of a firm, measured as the standard deviation of future asset returns. Suppose further there exists a competitive market for credit with diversified and thus risk-neutral suppliers. ${ }^{5}$ Creditors would price any marginal change in asset - and thus default - risk $\triangle \sigma_{V}$ by adjusting their required rate of return by $\triangle \delta_{D}$ such that the value of their claim $\widehat{D}$ is not affected:

$$
\triangle \widehat{D}\left(\triangle \sigma_{V}\right)+\triangle \widehat{D}\left(\triangle \delta_{D}\right)=0
$$

Take as given $\widehat{D}\left(\delta_{D}, \sigma_{V}, \cdot\right)$, describing bond value as a function of the cost of debt, asset volatility, and other pricing parameters. Observing the risk-free rate $r$ and the value of a risk-free bond $\widehat{D}\left(\delta_{D}=r, \sigma_{V}=0, \cdot\right)$, it is (generally) possible to infer the cost of debt

\footnotetext{
${ }^{4}$ For example, compare Eom et al. (2004), Bharath and Shumway (2008), Campbell et al. (2008).

${ }^{5}$ These are hypothetical assumptions only used to provide an intuition.
} 
for any level of asset variance and given set of pricing parameters using Equation $27{ }^{6}$

In line with this intuition, I define a model implied credit spread (MICS) $\lambda^{*}$ as the premium that needs to be paid to bondholders on top of the risk-free rate to offset the impact of an increase in asset variance - from zero to the actual level - on the value of debt. In a plain vanilla framework, firm value is exogenous and $\lambda^{*}$ can therefore equivalently be derived from equity values $\widehat{E}\left(\delta_{D}, \sigma_{V}, \cdot\right)$.

As an illustration, consider Figure 1, displaying isolines of debt and equity values as a function of the risk premium on debt $\lambda$, and firm risk $\sigma_{V}$ as they are implied by plain vanilla option pricing formulae. ${ }^{7}$ For the chosen set of parameters, the debt (equity) claim of a firm with zero asset variance $\sigma_{V}$ (and thus no risk of default) is approximately worth $100(50)$. When increasing $\sigma_{V}$ to $\sigma_{V}^{*}=.4$, approximately 15 units of wealth are transferred from bond- to shareholders. This discount on debt reflects the increased risk of default faced by creditors. To offset this wealth effect, $\lambda$ needs to be raised to approximately $\lambda^{*}=4.2 \%$.

[Figure 1 about here.]

While in the simple framework firm value is exogenous and always totals 150 , this is not the case in a barrier option framework. In such a framework, $\lambda^{*}$ can therefore only be directly inferred by considering the sensitivities of debt to changes in pricing parameters. Figure 2, displays isolines of debt values as a function of $\lambda$ and $\sigma_{V}$ as implied by barrier option pricing formulae.

\footnotetext{
${ }^{6}$ Restrictions on $\widehat{D}$ guaranteeing the existence and uniqueness of a solution are not discussed here for brevity. $\widehat{D}$ as defined in this study meets these restrictions over the range of realistic parameter combinations.

${ }^{7} \lambda$ enters the valuation of equity and debt as contingent claims via the aggregate payout ratio to debt and equityholders, $\delta_{V}$, as described by Equation 13 .
} 
[Figure 2 about here.]

Here, the increased risk faced by debtholders due to a premature knockout of debt is reflected in a clearly higher premium $\lambda^{*}$ required to offset the wealth effect on debt.

\subsubsection{Calculation}

MICS depend on the sensitivity of debt and equity to changes in firm risk $\sigma_{V}$ and interest payments to debtholders $\delta_{D}$. In a plain-vanilla pricing framework,

$$
\frac{\partial V}{\partial \sigma_{V}}=\frac{\partial C}{\partial \sigma_{V}}-\frac{\partial P}{\partial \sigma_{V}}
$$

and

$$
\frac{\partial V}{\partial \delta_{D}}=\frac{\partial C}{\partial \delta_{D}}-\frac{\partial P}{\partial \delta_{D}}+\frac{\partial \Delta_{D}}{\partial \delta_{D}}
$$

As firm value is exogenous in a plain vanilla framework $\left(\partial V / \partial \sigma_{V}=0\right.$ and $\partial V / \partial \delta_{D}=$ $0)$,

$$
\frac{\partial C}{\partial \sigma_{V}}=-\left(-\frac{\partial P}{\partial \sigma_{V}}\right)
$$

and

$$
\frac{\partial C}{\partial \delta_{D}}=-\left(-\frac{\partial P}{\partial \delta_{D}}+\frac{\partial \Delta_{D}}{\partial \delta_{D}}\right), 8
$$

where

$$
\frac{\partial \Delta_{D}}{\partial \delta_{D}}=T V e^{-\delta_{V} T}
$$

\footnotetext{
${ }^{8}$ The two consecutive minus signs illustrate that an increase (decrease) in shareholder value due to changes in $\delta_{D}$ or $\sigma_{V}$ corresponds to a decrease (increase) in debtholder value.

${ }^{9}$ This follows from Equations 1-3. For a detailed derivation, see Appendix A-1.
} 
$\lambda^{*}$ can therefore be calculated by solving any of the following equations:

$$
\begin{gathered}
\left.\widehat{D}_{\delta_{D}=r}\right|_{\sigma_{V}=0} ^{\sigma_{V}=\sigma_{V}^{*}}=-\left.\widehat{D}_{\sigma_{V}=\sigma_{V}^{*}}\right|_{\delta_{D}=r} ^{\delta_{D}=r+\lambda^{*}} \\
\left.\widehat{E}_{\delta_{D}=r}\right|_{\sigma_{V}=0} ^{\sigma_{V}=\sigma_{V}^{*}}=-\left.\widehat{E}_{\sigma_{V}=\sigma_{V}^{*}}\right|_{\delta_{D}=r} ^{\delta_{D}=r+\lambda^{*}} \\
\left.\widehat{D}_{\delta_{D}=r}\right|_{\sigma_{V}=0} ^{\sigma_{V}=\sigma_{V}^{*}}=\left.\widehat{E}_{\sigma_{V}=\sigma_{V}^{*}}\right|_{\delta_{D}=r} ^{\delta_{D}=r+\lambda^{*}} \\
\left.\widehat{E}_{\delta_{D}=r}\right|_{\sigma_{V}=0} ^{\sigma_{V}=\sigma_{V}^{*}}=\left.\widehat{D}_{\sigma_{V}=\sigma_{V}^{*}}\right|_{\delta_{D}=r} ^{\delta_{D}=r+\lambda^{*}}
\end{gathered}
$$

In the barrier option framework described by Equations 1, 5 and 6 ,

$$
\frac{\partial V}{\partial \sigma_{V}}=\frac{\partial C_{D O}}{\partial \sigma_{V}}-\frac{\partial P_{D O}}{\partial \sigma_{V}}+\frac{\partial \Delta_{D}^{\star}}{\partial \sigma_{V}}+\frac{\partial \Delta_{E}^{\star}}{\partial \sigma_{V}}
$$

and

$$
\frac{\partial V}{\partial \delta_{D}}=\frac{\partial C_{D O}}{\partial \delta_{D}}-\frac{\partial P_{D O}}{\partial \delta_{D}}+\frac{\partial \Delta_{D}^{\star}}{\partial \delta_{D}}+\frac{\partial \Delta_{E}^{\star}}{\partial \delta_{D}} \cdot{ }^{10}
$$

Given asset liquidation at bankruptcy, firm value is no longer exogenous. A premature knock-out of the down-and-out call and put options destroys both debt- and shareholder value. In this framework, it is thus possible that an increase in asset variance at the same time decreases the value of both, the debt and the equity claim. Here, $\lambda^{*}$ therefore can only be derived by solving Equation 33, describing changes in debt values. Specifically,

\footnotetext{
${ }^{10}$ The last two summands in both equations are not equal to zero as changes in $\sigma_{V}$ and $\delta_{V}$ affect the probability of a premature option knockout and thus the expected value of payouts.
} 
$\lambda^{*}$ can be obtained numerically by solving Equation 39 for $\lambda^{*}:{ }^{11}$

$$
\begin{gathered}
P_{D O}\left(\delta_{D}=r, \sigma_{V}=0\right)-\Delta_{V}^{\star}\left(\delta_{D}=r, \sigma_{V}=0\right) \\
=P_{D O}\left(\delta_{D}=r+\lambda^{*}, \sigma_{V}=\sigma_{V}^{*}\right)-\Delta_{V}^{\star}\left(\delta_{D}=r+\lambda^{*}, \sigma_{V}=\sigma_{V}^{*}\right) .
\end{gathered}
$$

Assuming all payouts to be made at debt maturity can substantially increase the number of cases for which no solution to Equation 39 exists. This reflects the fact that given the possibility of premature default in the barrier option framework - a firm may not be able to credibly commit to pay their interests in the far future and thus not be able to access debt financing at all. To avoid this problem, I assume payouts to be made on an annual basis until debt expiration. ${ }^{12}$ As payments are only made if the barrier has not yet been hit, I calculate the value of $\Delta_{V}^{\star}$ as the sum of a series of down-and-in options' rebates:

$$
\Delta_{V}^{\star}=\sum_{t=1}^{T}\left[\frac{\Delta_{V}}{T}\left(N\left(d_{1}(B, V)-\sigma_{V} \sqrt{t}\right)-\left(\frac{B}{V}\right)^{2 \eta-2} N\left(d_{1}(V, B)-\sigma_{V} \sqrt{t}\right)\right)\right] .{ }^{13}
$$

Finally, I extract the probability of default from $\lambda^{*}$ as

$$
\pi_{M I C S}=\frac{1-e^{-\lambda^{*}}}{L G D}
$$

\footnotetext{
${ }^{11}$ For a detailed derivation, see Appendix A-2. The level of tolerance for numerical convergence used throughout the entire analysis is E-10.

${ }^{12}$ Changing the frequency of payments - for example to semi-annual payments - does not change results significantly.

${ }^{13}$ The annual payments $\Delta_{V} / \mathrm{T}$ are not discounted by $e^{-r t}$, as the rebate is according to the valuation formula, as they are present values. Their future value is $\Delta_{V} / T e^{r t}$ which, discounted, equals $\Delta_{V} / T$.
} 


\section{Numerical Analysis}

Before applying the presented concepts to bankruptcy prediction in an empirical setting, a brief numerical analysis of the sensitivity of $\pi_{M I C S}$ and $\pi_{D D}$ to changes in input parameters provides an understanding of the differences between the two underlying approaches. As the simple Merton model of capital structure is clearly more widespread in the literature than the barrier option framework, most of the analysis is restricted to this simple model. An exception is the discussion of the sensitivity of $\pi_{M I C S}$ and $\pi_{D D}$ to changes to the most relevant parameters leverage and firm risk.

Figure 3 displays the relationship between leverage and default probabilities $\pi_{M I C S}$ and $\pi_{D D}$ for low-risk $\left(\sigma_{V}=.2\right)$, average-risk $\left(\sigma_{V}=.4\right)$ and high-risk $\left(\sigma_{V}=.8\right)$ firms. For any level of firm risk, $\pi_{M I C S}$ is higher than $\pi_{D D}$ for firms with low leverage and lower than $\pi_{D D}$ for firms with high leverage. The higher firm risk, the lower the leverage ratio at which the two functions cross each other. For the firms with the highest asset variance displayed, $\pi_{M I C S}$ is clearly above zero even for low-levered firms, while $\pi_{D D}$ is virtually equal to zero.

[Figure 3 about here.]

Figure 4 shows $\pi_{M I C S}$ and $\pi_{D D}$ as a function of asset volatility $\sigma_{V}$ for different leverage ratios. A similar effect as outlined before is observable. For low levels of asset risk, $\pi_{M I C S}$ is higher than $\pi_{D D}$, while for high levels of asset risk it is lower. Analogous to Figure 3, the higher the leverage, the lower $\sigma_{V}$ at the intersection of the two functions.

[Figure 4 about here.]

Figure 5 presents these relationships in three dimensions. The clear differences in the 
shapes of the two graphs illustrate that the two measures yield a different ordering of firms according to their bankruptcy probability.

[Figure 5 about here.]

Leverage and firm risk are two parameters intimately connected to the risk of default. It is therefore worthwhile to examine the impact of the assumption of path dependency has on the two measures of default probability. Figure 6 displays the relation between these variables assuming a bankruptcy barrier equal to $50 \%$ of total debt. Not surprisingly, the introduction of a positive barrier increases both measures. The graphs reveal two important characteristics of $\pi_{M I C S}$ and $\pi_{D D-B}$. First, increasing the barrier level increases the probability of default for firms with low leverage or low volatility. While this change is only marginal for $\pi_{D D-B}$, the impact of a positive barrier on $\pi_{M I C S}$ of such safe firms is strikingly pronounced for firms with high debt loads and low asset risk. Second, while the shape of the $\pi_{M I C S}$ function evolves significantly with changing barriers, the shape of the $\pi_{D D-B}$ function remains very similar. Adding path dependency as a feature to the simple model of capital structure can thus only have a little impact on the performance of the DD measure applied to bankruptcy prediction or bond pricing, while it significantly affects the fit of $\pi_{M I C S}$ to the data.

[Figure 6 about here.]

In the light of precedent empirical evidence, the observed behavior of $\pi_{M I C S}$ relative to $\pi_{D D}$ is appealing. Taken together, default estimates derived from model implied credit spreads are higher for relatively safe firms and lower for the riskiest firms. Recalling the previously cited conclusion by Eom et al. (2004), according to which structural models 
underestimate (real-world) credit spreads of safe bonds with low leverage and volatility, a future application of model implied credit spreads to bond pricing seems promising.

Both $\pi_{M I C S}$ and $\pi_{D D}$ are a decreasing function of the risk-free rate $r$, as shown in Figure 7. The reason is, of course, that $r$ is a component of the drift rate of the stochastic process assumed in the pricing framework. ${ }^{14}$ The higher this drift rate, the faster the call option moves deep into the money and the safer the debt. For firms with relatively low asset risk and leverage, $\pi_{M I C S}$ is more sensitive to changes in $r$ than $\pi_{D D}$. For higher numbers, the two functions are more parallel. ${ }^{15}$

[Figure 7 about here.]

As outlined in Section 5.2 , when calculating $\pi_{M I C S}\left(\pi_{D D}\right)$, an equal time to maturity of 6 years ( 1 year) will be assumed for all observations. While a sensitivity analysis in this case does not tell anything about variations in the two measures across observations and along time, it is useful to understand the term structures of default implied by the two approaches. Those are depicted in Figure 8 for different variance-leverage combinations.

[Figure 8 about here.]

The shapes of all functions share two common characteristics typical for structural models. First, all functions start in the origin. This implies that - even for high firm risk and leverage - the instantaneous probability of default is predicted to be zero. This unsatisfactory feature can be improved by introducing jumps in the stochastic process underlying the model. Second, the probability of default converges toward zero over very long-term horizons (not displayed), assuming positive drift rates and reasonable asset

\footnotetext{
${ }^{14} \mathrm{As}$ in Section 5.2, the drift rate assumed in the Merton model equals $r$ plus an equity premium of $6 \%$.

${ }^{15}$ Only moderate levels of firm risk and leverage are shown for displaying purposes.
} 
variances. The reason is that under these assumptions and given constant debt levels, the distribution of asset values moves away from the strike price over time. Incorporating mean-reverting leverage ratios, as done by Collin-Dufresne and Goldstein (2001), allows for non-zero default probabilities over infinite time horizons. ${ }^{16}$

In summary, the numerical analysis serves two purposes. First, it shows that there are substantial differences between the $\pi_{M I C S}$ and the $\pi_{D D}$ measure. Of course, this is the necessary condition for an outperformance of the $\pi_{M I C S}$ measure in an empirical context. Furthermore, the analysis illustrates that the $\pi_{M I C S}$ measure possesses desirable features as compared to the $\pi_{D D}$ which can help to explain the empirical results discussed in the following.

\section{Empirical Analysis}

\subsection{Data and Sample Selection}

Empirically testing the measures' ability to predict corporate default requires data on defaults, as well as variables for calculating pricing parameters.

I construct a bankruptcy indicator for the years 1980 to 2008 based on the AltmanNYU Salomon Center Bankruptcy list, including all Chapter 11 bankruptcy filings made by firms with liabilities equal to or greater than $\$ 100$ million at the time of default. I extend this list to include smaller firms relying on the sources used by Chava and Jarrow (2004) to construct their bankruptcy indicator. Specifically, I add all bankruptcy filings reported in the Wall Street Journal Index, the SDC database, SEC filings, and the CCH Capital Changes Reporter. My indicator is set to one in a month a company filed for

\footnotetext{
${ }^{16}$ For details on the term structure of credit risk in structural and reduced form models, see Duffie and Singleton (2003), pp.114-116.
} 
protection under Chapter 7 or Chapter 11 and to zero otherwise. ${ }^{17}$ If a firm files for bankruptcy several times, only the earliest month is used. Following Campbell et al. (2008), I additionally construct a broader indicator of corporate failure which extends the bankruptcy indicator by delistings due to poor stock performance (I include all CRSP delistings with delisting code 552), as well as D-ratings.

I construct pricing parameters on a monthly basis combining quarterly accounting data from Compustat with daily and monthly stock data from CRSP. ${ }^{18}$ Furthermore, I obtain interest rates on constant maturity treasury securities from the Federal Reserve Board of Governors. ${ }^{19}$

While information on bankruptcies and failures is also available for the $60 \mathrm{~s}$ and $70 \mathrm{~s}$, I restrict my analysis to the period starting 1980 for two reasons. First, quarterly accounting data is available for a broad cross-section only since the mid-seventies; including earlier years requires combining supplementing quarterly data with less timely annual data. $^{20}$ Even on an annual basis, debt items are only scarcely available before $1971 .^{21}$ Second, the Bankruptcy Reform Act of 1978 fundamentally changed the law governing bankruptcies. It took effect in October 1979 and made it easier for companies to file for protection from creditors. This change is only one out of several reasons for the strong increases in the number of defaults in later years. ${ }^{22}$ However, in contrast to other factors - such as changes in capital structure and idiosyncratic risk - it is not captured by the

\footnotetext{
${ }^{17}$ The Chava and Jarrow (2004) indicator is also used in Campbell et al. (2008) and Campbell et al. (2010). It comprises all firms in the Shumway (2001) dataset and in Moody's public firm database.

${ }^{18}$ Accounting items include total assets, debt in current liabilities, total long-term debt, total liabilities, net income, and the primary SIC code (Compustat items ATQ, DLCQ, DLTTQ, LT, NI, and SIC respectively). Equity data includes the number of shares outstanding, stock price, stock returns, returns on the value weighted S\&P500 index and its total market capitalization (CRSP items PRC, SHROUT, RET, VWRETD, and TOTVAL) on a monthly, and stock returns (RET) on a daily level.

${ }^{19}$ Taken from the H.15 file which can be downloaded at www.federalreserve.gov.

${ }^{20}$ See Wei (2006) and Campbell et al. (2010).

${ }^{21}$ See Vassalou and Xing (2004).

${ }^{22}$ See Campbell et al. (2008).
} 
pricing parameters.

After excluding all observations for which not all necessary data are available, my sample includes 1,647 failures, 959 bankruptcies and 1,625,169 firm-months observations. ${ }^{23}$

In addition to the pricing parameters, I compute the set of variables which Campbell et al. (2008) identify as powerful predictors of corporate failure. They are defined as follows: TLMTA, NIMTA, and CASHMTA are measured as the ratios of total liabilities, net income, as well as cash and short term assets to the market value of total assets (equal to the sum of the market value of equity and the book value of liabilities), respectively. Relative firm size RSIZE is defined as the logarithm of the market value of a firm's equity relative to the market capitalization of the S\&P500, MB as the market-to-book ratio, PRICE as the logarithm of the stock price winsorized above $\$ 15$, EXRET as a stock's excess returns over the S\&P500 during the last month, and SIGMA as the standard deviation of daily stock returns over the last three months. All variables except for PRICE are winsorized at their $5^{\text {th }}$ and $95^{\text {th }}$ percentile.

Campbell et al. (2008)'s logit regression of failure on the set of variables constitutes the current state-of-the art statistical model for bankruptcy prediction and by far outperforms the standard Merton (1974) DD measure. I therefore use their model as a benchmark against which I test the performance of $\pi_{M I C S}$ and $\pi_{D D-B}$ in a multivariate setting. Table 1 displays descriptive sample statistics for the Campbell et al. (2008) set of variables. Not surprisingly, the median defaulting firm exhibits a lower profitability, liquidity, stock price, size, and excess return, and higher leverage and asset risk than the

\footnotetext{
${ }^{23}$ In contrast to multiple related studies, I follow Campbell et al. (2008) and do not exclude firms in the financial services sector. While - due to their socio-economic importance - some financial services firms may receive some kind of governmental support or face additional restrictions when approaching default, this argument only applies to very few firms. All results are robust to excluding financial services firms and utilities, as shown in Section 5.4.
} 
median firm of the aggregate sample.

[Table 1 about here.]

\subsection{Parametrization}

Similar sets of parameters need to be estimated for calculating probabilities of default based on the DD measure $\pi_{D D-B}$ and model implied credit spreads $\pi_{M I C S}$. The assumptions underlying my estimates, their impact on the results, as well as alternative definitions used in related literature are discussed in the following.

Strike Price Equivalents. In a firm financed with equity and one zero coupon bond, equity is a call option on the firm with the strike price equal to the face value of total debt. When debt matures, stockholders can choose to either buy the entire firm from bondholders by paying them off the face value, or to roll over debt for another term. In reality, capital structures are typically more complex and combine numerous financing instruments with different maturities, seniorities, and embedded options. The choice of the strike price parameter thus depends on the perspective taken in a model.

When assessing a firm's risk of defaulting during the next year using the DD model, it makes sense not to consider the full amount of debt on the balance sheet. Long-term debt provides a firm in financial distress with additional breathing space, as the firm does not have to raise the cash for paying off this debt in the near future. Most recent studies computing Merton's DD measure therefore follow Crosbie and Bohn (2003), who define the strike price as the amount of short-term debt plus $50 \%$ of long-term debt.

In contrast, long-term debt does matter when assessing the impact of changes in asset risk on the option value of debt in the derivation of $\pi_{M I C S}$. While the predictive power 
of $\pi_{M I C S}$ increases when setting the strike price equal to total debt or total liabilities, I compute both $\pi_{D D-B}$ and $\pi_{M I C S}$ using the definition by Crosbie and Bohn (2003) for the sake of comparability. ${ }^{24}$

Spot Price Equivalents. The spot price equals the - unobservable - market value of firm assets which in turn is the sum of the market value of equity and the market value of debt. A simple way of defining the spot price is thus as the strike price plus the market value of equity. However, as the strike price is correctly defined using book values, this definition can overstate the market value of debt and thus the spot price, which is particularly likely for firms with deteriorating credit quality. Several recent studies therefore derive asset values as they are implied by observable equity values. Assuming that equity can be valued as a call option on firm assets, the market value of assets can be inferred numerically as the value that solves the according pricing equations for the correct market value of equity.

I have two concerns about this approach. First, the resulting values are sensitive to the underlying assumptions about the time to maturity of the option. Assuming a time to maturity of one year consistent with the short-term view taken in the DD model, the time values of equity and debt are relatively low such that this procedure yields estimates fairly close to those using book values of debt. Second, this approach by definition assumes book values of debt to be upward-biased estimates of market values of debt if cash-payouts to bondholders are ignored, as they have been in recent research. However, whether or not the book value of debt over- or understates its market value depends on the conditions under which debt contracts were negotiated and on unexpected

\footnotetext{
${ }^{24}$ As explicitly discussed in Eom et al. (2004), pp. 524f, non-debt liabilities are relevant for the pricing of debt, too.
} 
changes in firm risk since the financing. I therefore follow Eom et al. (2004) and define spot prices as the sum of the strike price and the market value of equity.

Asset Variance. Several ways of estimating asset variance exist in the literature. ${ }^{25}$ Many use the observable volatility of past stock returns as a starting point and derive estimates of asset risk based on assumptions about the relation between equity and firm returns.

One approach that accounts for the riskiness of distressed debt uses the "optimal hedge equation" known from delta-hedging to describe the relationship between equity and firm risk:

$$
\sigma_{V}=\frac{\sigma_{E}}{\left(1+\frac{D}{E}\right) N\left(d_{1}\right)}
$$

where $d_{1}$ is defined according to Equation $11 .{ }^{26} N\left(d_{1}\right)$ measures the sensitivity of option values to changes in the underlying. For zero drift rates, it is close to .5 for at the money options - corresponding to firms in or close to financial distress - and approaches one as the moneyness increases. Equation 42 thus imposes an assumption about the riskiness of debt consistent with the contingent claims framework. It implies that the value of debt behaves in the same way as the value of a short put on firm assets.

One concern about the application of this relationship is its stationarity. As known from delta hedging, the relationship described by Equation 42 only holds instantaneously. As soon as the value of the underlying changes, deltas change as well - especially for at the money options. Crosbie and Bohn (2003) therefore conclude that "in practice, the market leverage moves around far too much to provide reasonable results" and propose alternative iterative estimation procedure. While the asset variance estimates based on

\footnotetext{
${ }^{25}$ The terms asset risk, asset variance, asset volatility and firm risk are used equivalently in the following.

${ }^{26}$ Note that, as $N\left(d_{1}\right)$ itself depends on $\sigma_{V}$, Equation 42 requires a numerical solution.
} 
their procedure are more constant over time, Bharath and Shumway (2008) label the procedure "complicated". After testing its empirical performance they conclude that "the iterative procedure used to solve the Merton model for default probability does not appear to be useful." Eom et al. (2004) note that the resulting values for asset variance actually do not differ substantially from the ones computed using the optimal hedge equation. I therefore define asset volatility according to Equation 42, computing $\sigma_{E}$ as the standard deviation of the last three months' daily stock returns. ${ }^{27}$

Time To Maturity. In the simple case where a firm is financed by equity and one zero coupon bond, the most intuitive way of defining the time to maturity of equity as a call option is as the maturity of the bond. At the time the bond expires - and not earlier - shareholders have the possibility not to roll the bond over, but to acquire the entire firm by paying off the entire debt. In reality, capital structures are more complex and consist of instruments with different maturities, coupon payments before maturity and embedded options that allow for early redemption. Attempting to capture at least a part of this complexity, Eom et al. (2004) price bonds with the Merton model by considering each payment - including coupon payments and the final payment of the principal - as an individual bond with a maturity equal to the date of the payment. As described in Crosbie and Bohn (2003), a different view underlies Moody's KMV model. Assuming the previously described short-term perspective, it identifies how distant a firm is from defaulting in one year. I therefore follow studies replicating their measure and adopt a

\footnotetext{
${ }^{27}$ Empirical results are robust to using the Crosbie and Bohn (2003) measure of asset volatility. The predictive power of both $\pi_{D D-B}$ and $\pi_{M I C S}$ slightly increases when using the simple but arbitrary measure of firm risk proposed in Bharath and Shumway (2008). As shown in an earlier version of this paper, incorporating additional information - for example about profitability and firm size - in the estimation of $\sigma_{V}$ can substantially increase their predictive power. Results based this innovative measure of firm risk are not presented in the current version of the article as they cannot be compared to the results of related studies.
} 
one year time to maturity when computing $\pi_{D D-B}$.

The intuition underlying $\pi_{M I C S}$ requires a different view. The measure is driven by call option sensitivity to changes in volatility and the payout ratio. Simply assuming a short-term horizon of one year despite of a far longer actual option term yields unrealistic sensitivities and thus unprecise default estimates. Given limited availability of information about the term structure of firms' liabilities, I simply set the time to maturity to six years. ${ }^{28}$ However, empirical results are not significantly altered when assuming a one-year time to maturity for the calculation of $\pi_{M I C S}$, too.

Drift Rate. The drift rate of the stochastic process is the difference between the assumed growth rate $\mu$ and the weighted payout to shareholders and debtholders $\delta_{V}$. It determines how fast assets move toward or away from the bankruptcy threshold and is therefore crucial to estimating the distance to default. However, recent literature does not agree about the correct estimation of this parameter. ${ }^{29}$ Given empirical evidence that underperforming firms are more likely to default, it is tempting to use past asset or equity returns as the future drift rate. However, projecting past under- or overperformance into the future implicitly requires the strong assumption of a misvaluation of firm assets today. When computing $\pi_{M I C S}$, I therefore follow Campbell et al. (2008) and use the risk free rate (which I obtain as the interest rate paid on one year constant

\footnotetext{
${ }^{28}$ See, for example, Brockman and Turtle (2003). An alternative approach involves using a weighted average measure of debt maturity based on the Compustat items debt due in one to five years from the reporting year. However, these items are less frequently available and less consistent with data on total liabilities for the early years of the sample period.

${ }^{29}$ Some studies suggested the use of past stock returns or the risk-free rate plus equity premium, while others use only the risk-free rate, or even assume a zero drift in asset values; see Crosbie and Bohn (2003), Vassalou and Xing (2004), Bharath and Shumway (2008) and Campbell et al. (2008), as well as Brockman and Turtle (2003) and Brown et al. (1995), respectively. Cash payouts to shareholders and debtholders are neglected in most studies. Amongst the studies cited in this article, only Eom et al. (2004) use the actual time to maturity. They are also the only ones capturing the impact of cash payouts in their model.
} 
maturity treasuries) plus an equity premium of .06 as growth rate instead. I reduce asset growth by a cash payout rate equal to the weighted average of dividend and interest rate payments (assumed to be equal to the 1-year risk-free rate plus a flat credit risk premium of .03), as described in Equation $13 .^{30}$

Fewer assumptions are needed when computing $\pi_{M I C S}$. First, the physical drift rate in assets is not required as an input parameter, since the risk-neutral valuation framework need not be abandoned. Instead, the assumed asset growth is risk-neutral and equal to the risk-free rate matched to the maturity of the option. As no 6-year rates on constant maturity treasuries are available, I construct a yield curve using cubic spline interpolation to obtain an estimate of the 6-year risk-free rate. ${ }^{31}$ Second, no assumptions are required about the payouts to debtholders. Rather, as described in Section 3.2, hypothetical payouts are derived that offset the reduction in bondholder wealth due to a positive asset risk.

Given the endogeneity of dividend payments, I assume the dividends of all firms to be zero when computing both $\pi_{D D-B}$ and $\pi_{M I C S}$. As a firm approaches financial distress, it will most likely stop paying dividends. All findings are robust to using the actual dividend rate instead.

\subsection{Statistical Models for Default Prediction}

Before presenting the results of the multivariate regression analysis, I comment on the recent discussion about the adequacy of logit models for bankruptcy prediction and the necessity of adjusting test statistics. Shumway (2001) criticizes probit and logit models

\footnotetext{
${ }^{30}$ Alternatively, payouts to debtholders can be approximated as accounting interest payments, which is avoided due to very limited data availability in the early years of the sample period.

${ }^{31}$ For details on cubic spline interpolation for yield curve construction, see Ron (2000).
} 
for not taking into account the duration of survival if applied to single-period data and proposes a hazard model instead. Even before his study, hazard models can be and have been employed using simple logit programs. Shumway (2001) admits that "estimating hazard models with a logit program is so simple and intuitive that it has been done by academics and researchers without a hazard model justification." ${ }^{22}$ Following Shumway (2001), Chava and Jarrow (2004) and Campbell et al. (2008), it therefore estimate the marginal probability of bankruptcy (or failure) over the next period as

$$
P_{t}\left(Y_{t+1}=1\right)=\frac{1}{1+e^{-\alpha-\beta \times X_{t}}}
$$

where $Y_{t}$ equals one if failure (or bankruptcy) occurs at time $\mathrm{t}$ and zero otherwise, $\alpha$ and $\beta$ are model parameters and $X_{t}$ is a matrix of time-varying covariates. Higher values of $\alpha+\beta \times X_{t}$ imply a higher probability of failure (or corporate default). ${ }^{33}$

One important question arising when using a logit program to estimate a hazard rate model is whether test statistics require adjustment. As argued by Shumway (2001), test statistics need to be adjusted for the fact that observations are not independent over time. ${ }^{34}$ He proposes to penalize the logit model for this lack of independence between observations by simply defining the sample size used for calculating test statistics as the actual sample size divided by the average number of monthly observations per firm.

\footnotetext{
${ }^{32}$ The main difference between an adjusted logit and a hazard model is the way how firm age can be accounted for as a potential factor driving the probability of bankruptcy. While in a logit model, some function of firm age can be simply included as additional explanatory variable, it enters the estimation of the hazard model more elegantly via the baseline hazard function. Given the insignificance of firm age for predicting bankruptcy reported by Shumway (2001), I follow Chava and Jarrow (2004) and Campbell et al. (2008) and estimate a hazard model using a logit program excluding firm age as explanatory variable.

${ }^{33}$ As outlined in Section 5.1, I differentiate between corporate failure and corporate default in the empirical analysis.

${ }^{34} \mathrm{~A}$ firm-month observation only enters the model at time $t$ if it has not defaulted at time $t-1$. In other words, the possibility of observing default or survival at a certain time is conditional on firm survival prior to that point in time.
} 
While his article only considers the adjustment of the Chi-Square statistics, the same argument can be used to justify an adjustment of t-statistics or pseudo- $R^{2}$ s. Contradicting his intuition, Chava and Jarrow (2004) argue that it is not necessary to assume interdependence between all observations for the unadjusted test statistics to be valid and conclude that "Shumway (2001)'s adjustment for the lack of the time series independence of a firm's bankruptcy variable is unnecessary."

I empirically test whether the time series dependence of the dependent variable biases regression results by comparing the results of the same regression model fitted using two different subgroups of my aggregate sample. ${ }^{35}$ The first (second) subsample is created by randomly splitting my sample along the cross-section (the time series) into two parts and dropping one of them. Given a one-to-one split, the second subsample thus contains observations with only half the number of firm-months per firm on average. For example, if ten monthly observations exist for the average firm in the aggregate sample, only approximately five monthly observations exist for the average firm in subsample two. In contrast, the first subsample still exhibits an average number of approximately ten monthly observations per firm, but only consists of half of the firms. If an adjustment for the lack of independence along the time series similar to the one proposed by Shumway (2001) indeed was necessary, regression results for models fitted using the two different data sets without any adjustment should differ significantly. Repeating the procedure 1,000 times and comparing the resulting distributions of standard errors, coefficient estimates, and pseudo- $R^{2} \mathrm{~s}$, I do not find any significant difference between models fitted using the first and second subsample. In line with Chava and Jarrow (2004), I therefore

\footnotetext{
${ }^{35}$ While beyond the scope of this study, a more rigorous way to assess the necessity of adjustments is to run a simulation. Then, the distributions of all variables together with their interdependence can be defined a priori such that all statistics can be assessed given the knowledge of the true set of parameters.
} 
do not adjust regression results in any way. ${ }^{36}$

\subsection{Results}

In the following, the measures' abilities to forecast default are assessed in a bivariate and multivariate setting. As outlined in Section 5.1, I use two different proxies for default, bankruptcy and failure. Bankruptcy is defined as any Chapter 7 or 11 filing. Failure extends bankruptcy by D-ratings and delistings due to poor stock performance.

Table 2 reports the results of a bivariate non-parametric test of $\pi_{M I C S}, \pi_{D D-B}$, and $\pi_{D D}$ to forecast bankruptcy and failure. To create this overview, I sort all firm-month observations by their $\pi$-value in a first step. In a second step, I count the number of defaults observed over the next period in each decile. The reported numbers are the percentages of all 959 bankruptcies (Panel 2(a)) and 1,647 failures (Panel 2(b)) assigned to each decile in that way. To show the robustness of my results to the exclusion of financial services firms which is common in related literature, I report bivariate results for the aggregate sample ("All"), as well as a sample excluding firms in the financial services sector (SIC codes 6000-6999). This restriction reduces the analysis to $1,363,268$ firm-month observations, 912 bankruptcies and 1,558 failures.

[Table 2 about here.]

Bivariate results indicate that $\pi_{M I C S}$ separates defaulting from non-defaulting firms more precisely than $\pi_{D D-B}$, and $\pi_{D D}$ for both the aggregate sample and the sample excluding financial services firms. Specifically, the share of bankruptcies and failures observed in the top $\pi_{M I C S}$ decile is higher than in the top $\pi_{D D-B}$, and $\pi_{D D}$ deciles.

\footnotetext{
${ }^{36}$ Results of this random sampling procedure are not reported explicitly as they do not add any insights beyond the non-necessity of adjustments.
} 
The superior performance of the $\pi_{M I C S}$ measure is confirmed in a multivariate setting. Table 3 reports results of logit regressions of the bankruptcy indicator on $\pi_{M I C S}, \pi_{D D-B}$, $\pi_{D D}$ and the set of control variables taken from Campbell et al. (2008). To avoid problems of multicolinearity, leverage TLMTA and volatility SIGMA are not included in models with any of the three predictors. Multivariate results are only reported for the aggregate sample but are robust to the exclusion of financial services firms.

[Table 3 about here.]

Various aspects indicate that $\pi_{M I C S}$ captures the probability of corporate default better than $\pi_{D D-B}$. First, the model including only $\pi_{M I C S}$ as an explanatory variable has a Pseudo $R^{2}$ of $18.6 \%$ (Column 1 ). This is clearly above the $R^{2}$ of $14.3 \%$ of the second model, which only includes $\pi_{D D-B}$ (Column 2). Second, combining $\pi_{M I C S}$ and $\pi_{D D-B}$ in one model does not increase the model fit (compare Column 1 to Column 3 and Column 4 to Column 6). Third, $\pi_{D D-B}$ does not enter regressions including both $\pi_{M I C S}$ and $\pi_{D D-B}$ significantly, while $\pi_{M I C S}$ does (see Column 3 and Column 6). Despite its superior performance, $\pi_{M I C S}$ predicts defaults less well as the set of predictors taken from Campbell et al. (2008) (Colum 7). The superior fit to the data is at least partly due to the fact that all predictors enter the regression independently.

Results of logit regressions including the failure indicator are almost identical to those including the bankruptcy indicator and are presented merely as a robustness check (see Table 4). While models 1 through 3 exhibit a slightly better fit to the data in terms of their $R^{2}, \pi_{M I C S}$ remains a better predictor of default than $\pi_{D D-B}$.

[Table 4 about here.] 


\section{Conclusion}

The contribution of this paper is threefold.

First, I propose a new method for extracting probability of default estimates from structural credit risk models. The method is applicable to all models assuming a contingent claims perspective on debt and equity and value these as a function of asset risk and payout ratio. The estimation procedure consists of two parts. In a first step, I numerically derive model implied credit spreads (MICS) from the increase in the payout to debtholders necessary to offset the impact of an increase in asset variance on the option value of debt and equity. In a second step, I calculate a risk-neutral probability of default from MICS in a similar way as default estimates are derived from credit spreads observed at markets. In contrast to real-world credit spreads, MICS do not contain risk premia for default timing and recovery uncertainty, thus yielding a purer estimate of physical default probabilities.

Second, I compare the properties of MICS default estimates derived assuming a simple Merton model of capital strucure to the expected default frequency from a Merton-type distance to default (DD) measure in a numerical analysis. Addressing the requirements highlighted in previous research, the proposed estimate takes on higher values for safe firms and lower values for firms with high leverage and asset volatility.

Third, I assess my measure's ability to predict bankruptcy and corporate failure relative to the DD measure in an empirical setting. As shown in both a bivariate and a multivariate setting, the MICS measure proves to capture default probabilities better than the DD measure. Results are robust to changes in the choice of pricing parameters and to variations in the sample selection. Future research should further explore the 
potential of the MICS approach by applying it to alternative structural models and by using it for the pricing of corporate bonds. 


\section{Appendix}

\section{A-1. Aggregate Firm Payout}

The present value of firm payouts $\left(\Delta_{V}\right)$ in a plain vanilla model of capital structure is the sum of the present value of payouts to debt and equity holders:

$$
\Delta_{V}=\Delta_{E}+\Delta_{D}
$$

From Equations 1-3 follows:

$$
\begin{aligned}
\Delta_{V}= & V-C-D^{*} e^{-r T}+P \\
= & V-\left[V e^{-\delta_{V} T} N\left(d_{1}(V, D)\right)-D e^{-r T} N\left(d_{1}(V, D)-\sigma_{V} \sqrt{T}\right)\right]-D^{*} e^{-r T} \\
& +\left[-V e^{-\delta_{V} T} N\left(-d_{1}(V, D)\right)+D e^{-r T} N\left(-d_{1}(V, D)+\sigma_{V} \sqrt{T}\right)\right] \\
= & V\left[1-e^{-\delta_{V} T} N\left(d_{1}(V, D)\right)-e^{-\delta_{V} T} N\left(-d_{1}(V, D)\right)\right] \\
& +D\left[e^{-r T} N\left(d_{1}(V, D)-\sigma_{V} \sqrt{T}\right)-e^{-r T}+e^{-r T} N\left(-d_{1}(V, D)+\sigma_{V} \sqrt{T}\right)\right] \\
= & V\left[1-e^{-\delta_{V} T}\right],
\end{aligned}
$$

where $N(\cdot)$ denotes the function describing the standard cumulative probability density and $d_{1}(V, D)$ is computed according to Equation 11. As the value of dividend streams $\left(\Delta_{E}\right)$ is not affected by changes in bondholders' interest rates,

$$
\frac{\partial \Delta_{D}}{\partial \delta_{D}}=\frac{\partial \Delta_{V}}{\partial \delta_{D}}=V T e^{-\delta_{V} T} .
$$




\section{A-2. Calculating Model Implied Credit Spreads}

MICS $\lambda^{*}$ can be calculated by numerically solving

$$
\begin{gathered}
\widehat{D}_{\delta_{D}}=\left.r\right|_{\sigma_{V}=0} ^{\sigma_{V}=\sigma_{V}^{*}}=-\left.\widehat{D}_{\sigma_{V}=\sigma_{V}^{*}}\right|_{\delta_{D}=r} ^{\delta_{D}=r+\lambda^{*}} \\
\Leftrightarrow \quad\left[D e^{-r T}-P_{D O}\left(\delta_{D}=r\right)+\Delta_{D}^{\star}\left(\delta_{D}=r\right)\right]_{\sigma_{V}=0}^{\sigma_{V}=\sigma_{V}^{*}} \\
=-\left[D e^{-r T}-P_{D O}\left(\sigma_{V}=\sigma_{V}^{*}\right)+\Delta_{D}^{\star}\left(\sigma_{V}=\sigma_{V}^{*}\right)\right]_{\delta_{D}=r}^{\delta_{D}=r+\lambda^{*}} \\
\Leftrightarrow \quad\left[-P_{D O}\left(\delta_{D}=r\right)+\Delta_{V}^{\star}\left(\delta_{D}=r\right)\right]_{\sigma_{V}=0}^{\sigma_{V}=\sigma_{V}^{*}} \\
\left.\Leftrightarrow \quad-P_{D O}\left(\sigma_{V}=\sigma_{V}^{*}\right)+\Delta_{V}^{\star}\left(\sigma_{V}=\sigma_{V}^{*}\right)\right]_{\delta_{D}=r}^{\delta_{D}=r+\lambda^{*}} \\
\Leftrightarrow \quad P_{D}\left(\delta_{D}=r, \sigma_{V}=\sigma_{V}^{*}\right)+\Delta_{V}^{\star}\left(\delta_{D}=r, \sigma_{V}=\sigma_{V}^{*}\right) \\
+P_{D O}\left(\delta_{D}=r, \sigma_{V}=0\right)-\Delta_{V}^{\star}\left(\delta_{D}=r, \sigma_{V}=0\right) \\
\Leftrightarrow \quad P_{D O}\left(\sigma_{V}=\sigma_{V}^{*}, \delta_{D}=r+\lambda^{*}\right)-\Delta_{V}^{\star}\left(\sigma_{V}=\sigma_{V}^{*}, \delta_{D}=r+\lambda^{*}\right) \\
-P_{D O}\left(\sigma_{V}=\sigma_{V}^{*}, \delta_{D}=r\right)+\Delta_{V}^{\star}\left(\sigma_{V}=\sigma_{V}^{*}, \delta_{D}=r\right) \\
P_{D O}\left(\delta_{D}=r, \sigma_{V}=0\right)-\Delta_{V}^{\star}\left(\delta_{D}=r, \sigma_{V}=0\right) \\
P_{D O}\left(\sigma_{V}=\sigma_{V}^{*}, \delta_{D}=r+\lambda^{*}\right)-\Delta_{V}^{\star}\left(\sigma_{V}=\sigma_{V}^{*}, \delta_{D}=r+\lambda^{*}\right) .
\end{gathered}
$$




\section{References}

Bharath, S., Shumway, T., 2008. Forecasting default with the merton distance to default model. Review of Financial Studies 21 (3), 1339-1369.

Black, F., Scholes, M., 1973. The pricing of options and corporate liabilities. Journal of Political Economy $81(3), 637-654$.

Brockman, P., Turtle, H., 2003. A barrier option framework for corporate security valuation. Journal of Financial Economics 67.

Brown, S., Goetzmann, W., Ross, S. W., 1995. Survival. Journal of Finance 50 (2), 853-873.

Campbell, J. Y., Hilscher, J., Szilagyi, J., 2008. In search of distress risk. Journal of Finance 63 (6), $2899-2939$.

Campbell, J. Y., Hilscher, J., Szilagyi, J., 2010. Predicting financial distress and the performance of distressed stocks. Harbard Business School, Working Paper.

Chava, S., Jarrow, R. A., 2004. Bankruptcy prediction with industry effects. Working Paper, Cornell University.

Collin-Dufresne, P., Goldstein, R. S., 2001. Do credit spreads reflect stationary leverage ratios? Journal of Finance 56 (5), 1929-1957.

Crosbie, P., Bohn, J., 2003. Modeling default risk. Working Paper, KMV Corporation.

Duffie, D., Singleton, K. J., 2003. Credit Risk - Pricing, Measurement, and Management. Princeton University Press.

Eom, Y. H., Helwege, J., Huang, J.-Z., 2004. Structural models of corporate bond pricing: An empirical analysis. Review of Financial Studies 17 (2), 499-544.

Merton, R. C., 1974. On the pricing of corporate debt: The risk structure of interest rates. Journal of Finance $29(2), 449-470$.

Ron, U., 2000. A practical guide to swap curv construction. Bank of Canada, Working Paper.

Rubinstein, M., Reiner, E., 1991. Breaking down the barriers. RISK 4.

Shumway, T., 2001. Forecasting bankruptcy more accurately: A simple hazard model. Journal of Business $74(1), 101-124$.

Vassalou, M., Xing, Y., 2004. Default risk in equity returns. Journal of Finance 59 (2), 831-868.

Wei, Steven X., Z. C., 2006. Why did individual stocks become more volatile? Journal of Business 79 (1), 
259-292. 


\section{List of Figures}

1 Option value as a function of asset volatility and the risk premium on debt 38

2 Option value as a function of asset volatility and the risk premium on debt 39

3 Default probabilities and leverage . . . . . . . . . . . . . . . . 40

4 Default probabilities and asset volatility .............. . . . . . . 41

$5 \quad$ Default probabilities, leverage and asset volatility . . . . . . . . . . 42

6 Default probabilities, leverage and asset volatility in extended framework 43

7 Default probabilities and risk-free rate . . . . . . . . . . . . . . 44

8 Default probabilities and time to maturity . . . . . . . . . . 45 

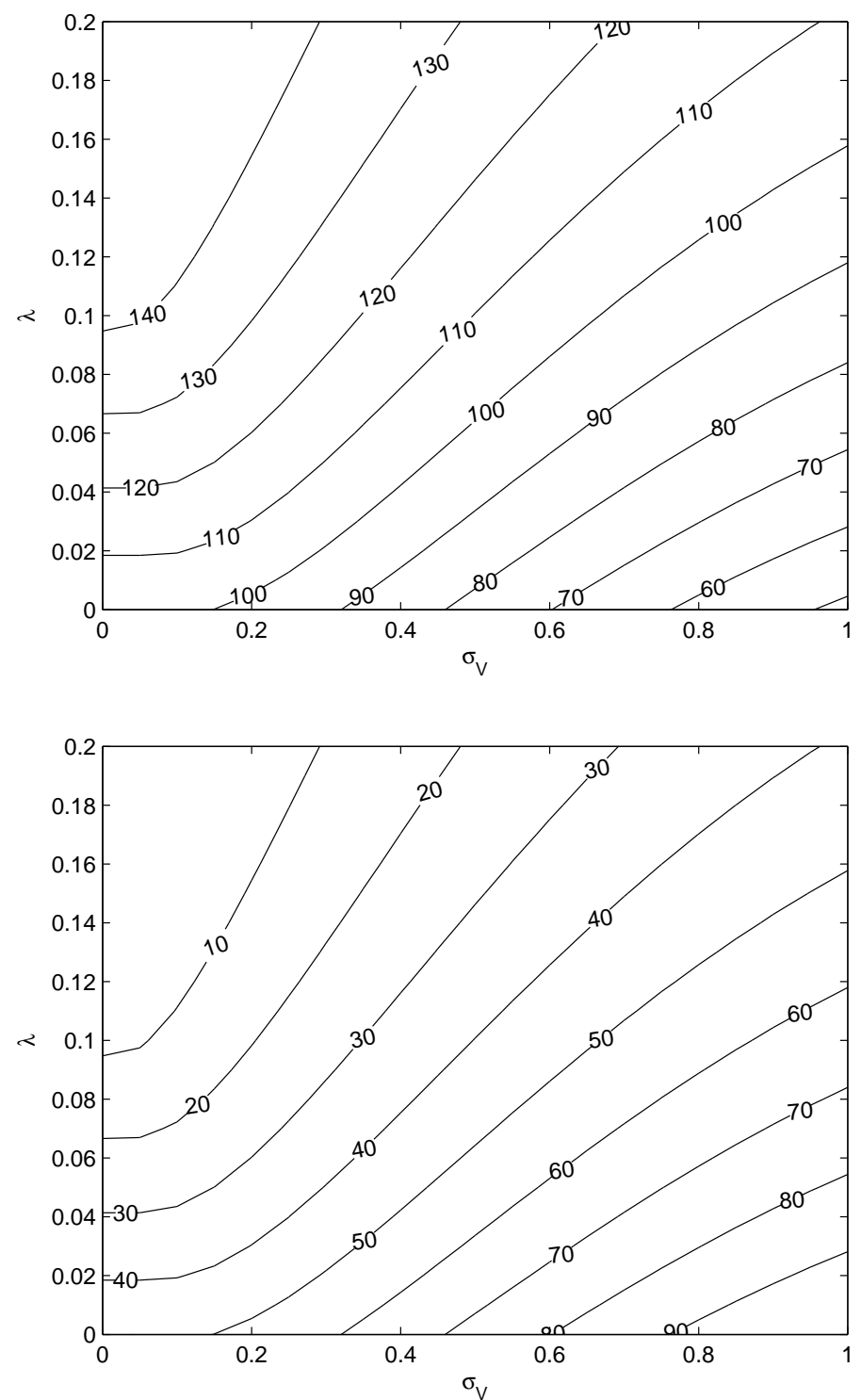

Figure 1: Values of equity and debt as plain vanilla options on firm assets computed as a function of asset volatility and the risk premium on debt.

The upper (lower) graph displays isolines of debt (equity) values as a function of asset volatility $\sigma_{V}$ and the risk premium on debt, $\lambda$. $(V=150, D=100, r=.05, T=6)$. 


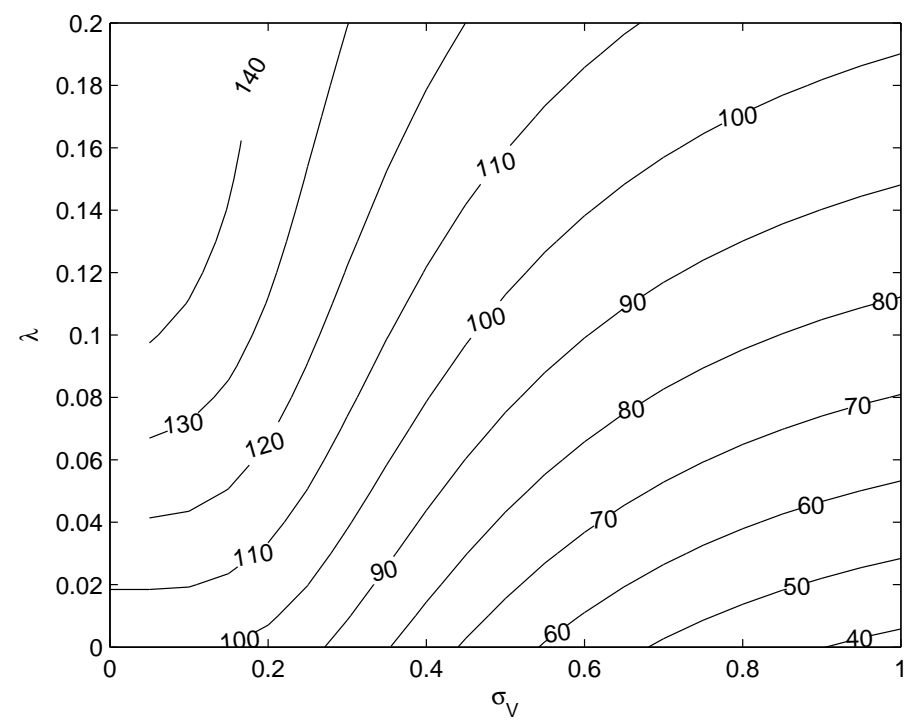

Figure 2: Value of debt as a barrier option on firm assets computed as a function of asset volatility and the risk premium on debt.

The graph displays isolines of debt values as a function of asset volatility $\sigma_{V}$ and the risk premium on debt, $\lambda$.

$(V=150, D=100, r=.05, T=6, B=50, L G D=.75$. $)$. 


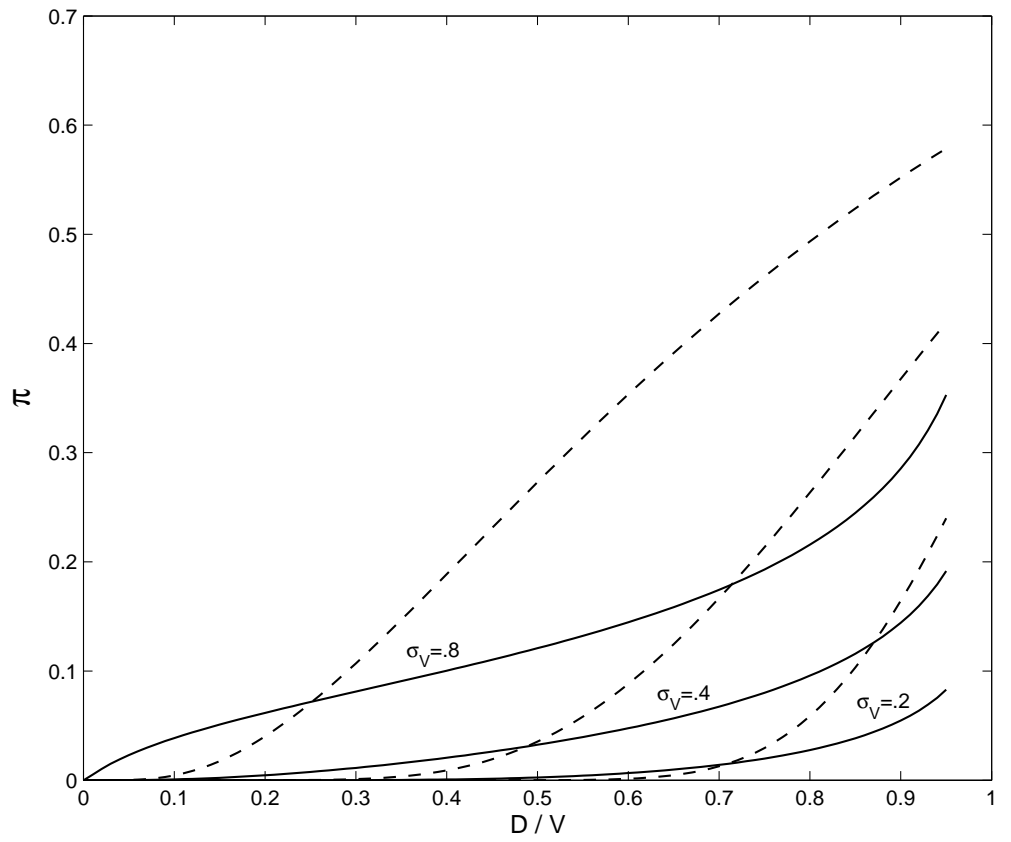

Figure 3: Estimated default probabilities as a function of leverage $D / V$ for different levels of asset variance $\sigma_{V}$.

The solid and dashed lines are probabilities of default estimated based on model implied credit spreads $\left(\pi_{M I C S}\right)$ and the Merton distance to default model $\left(\pi_{D D}\right)$, respectively.

$\left(V=100, r=.05, T_{M I C S}=6, T_{D D}=1, \mu_{D D}=\mathrm{r}+.06, \delta_{E}=0, \mathrm{LGD}=.75\right)$. 


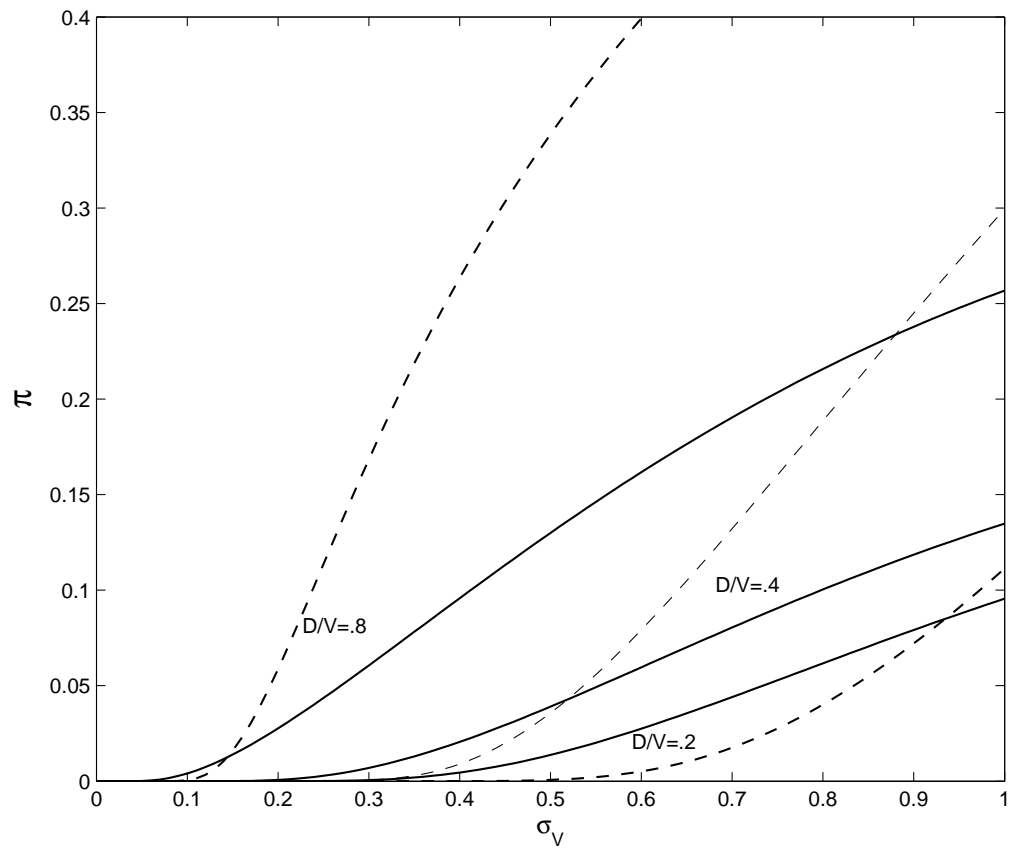

Figure 4: Estimated default probabilities as a function of asset volatility $\sigma_{V}$ for different levels of leverage $D / V$.

The solid and dashed lines are probabilities of default estimated based on model implied credit spreads $\left(\pi_{M I C S}\right)$ and the Merton distance to default model $\left(\pi_{D D}\right)$, respectively. The graph is cut-off at $\pi=.4$ for displaying purposes.

$\left(V=100, r=.05, T_{M I C S}=6, T_{D D}=1, \mu_{D D}=\mathrm{r}+.06, \delta_{E}=0, \mathrm{LGD}=.75\right)$. 


$$
\text { : }
$$



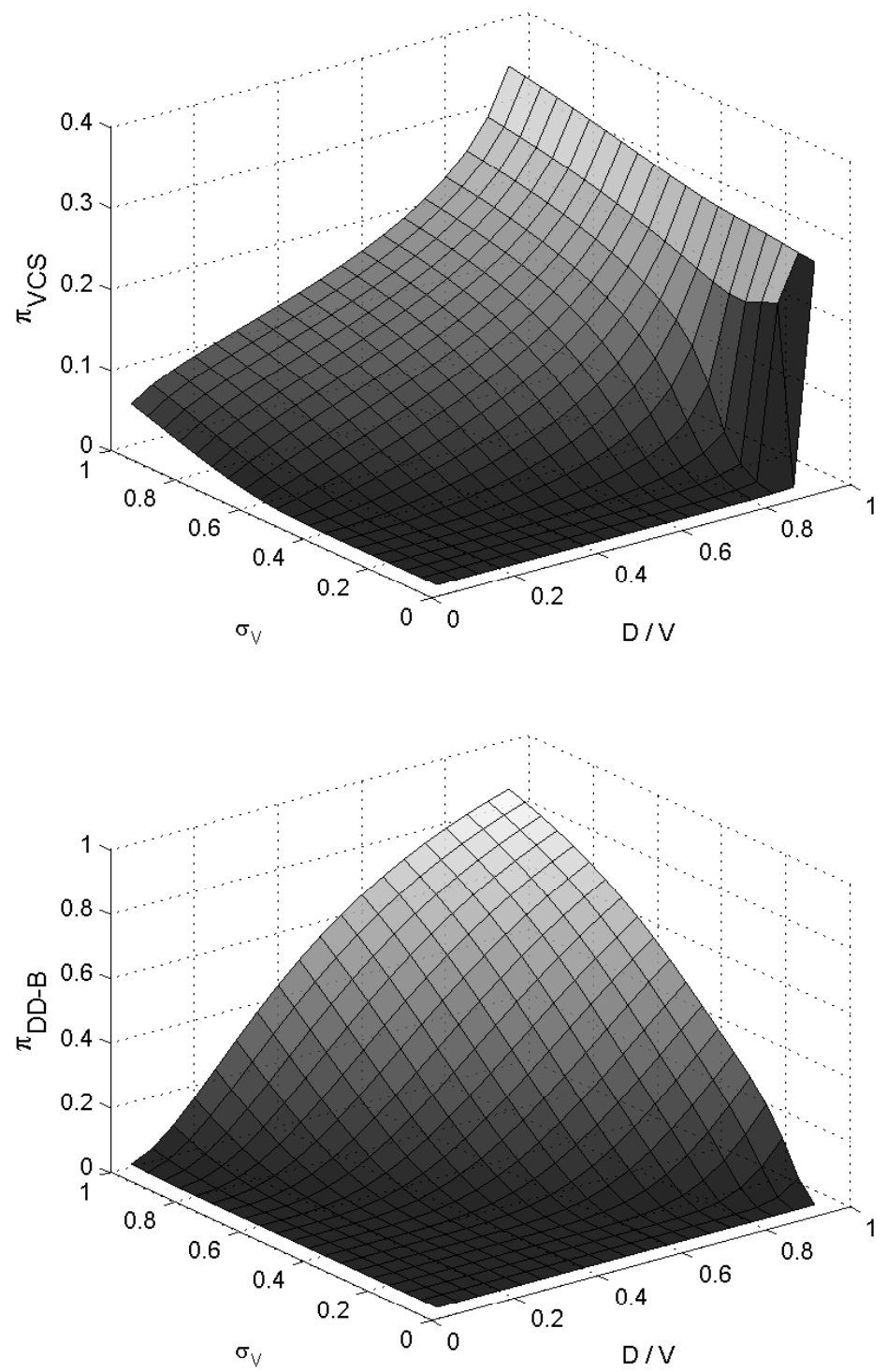

Figure 6: Estimated default probabilities as a function of asset volatility $\sigma_{V}$ and leverage $D / V$.

The upper and the lower graph display probabilities of default estimated based on model implied credit spreads $\left(\pi_{M I C S}\right)$ and a distance to default model $\left(\pi_{D D-B}\right)$ and assuming a barrier option model of capital structure.

$\left(V=100, r=.05, T_{M I C S}=6, T_{D D}=1, \mu_{D D}=\mathrm{r}+.06, \delta_{E}=0, B=50, \mathrm{LGD}=.75\right)$. 


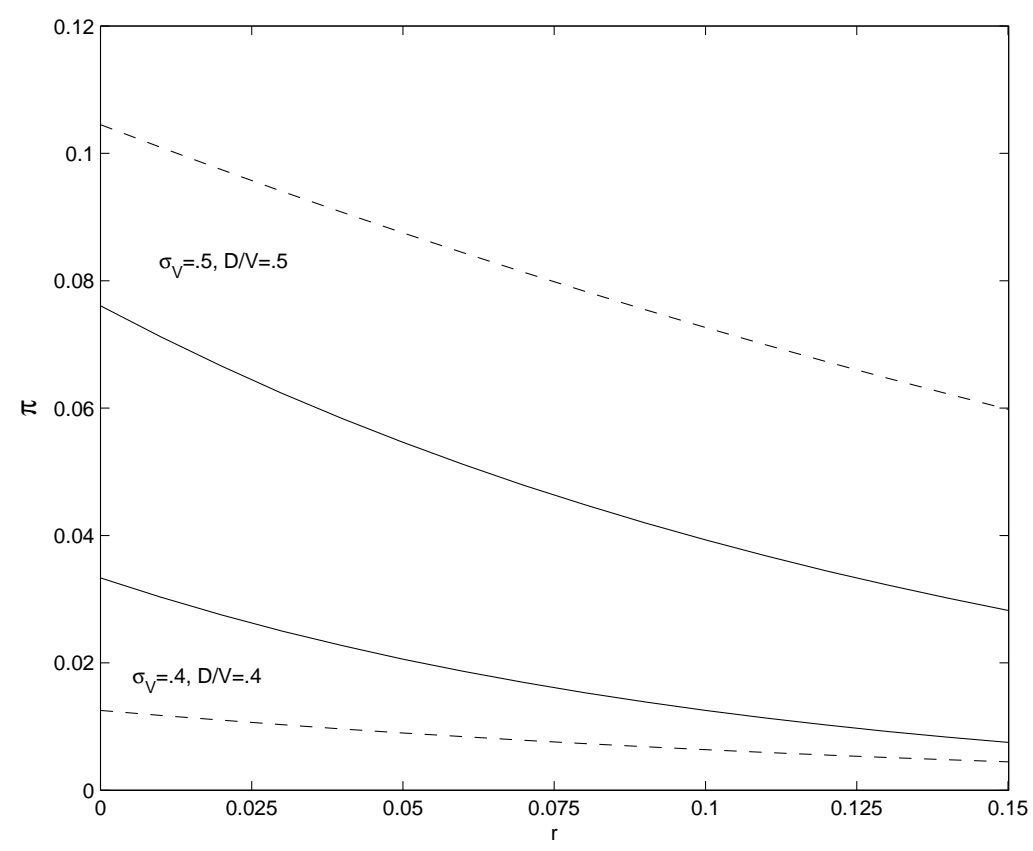

Figure 7: Estimated default probabilities as a function of risk-free rate $r$ for different levels of asset volatility $\sigma_{V}$ and leverage $D / V$.

The solid and dashed lines are probabilities of default estimated based on model implied credit spreads $\left(\pi_{M I C S}\right)$ and the Merton distance to default model $\left(\pi_{D D}\right)$, respectively. $\left(V=100, T_{M I C S}=6, T_{D D}=1, \mu_{D D}=\mathrm{r}+.06, \delta_{E}=0, \mathrm{LGD}=.75\right)$. 


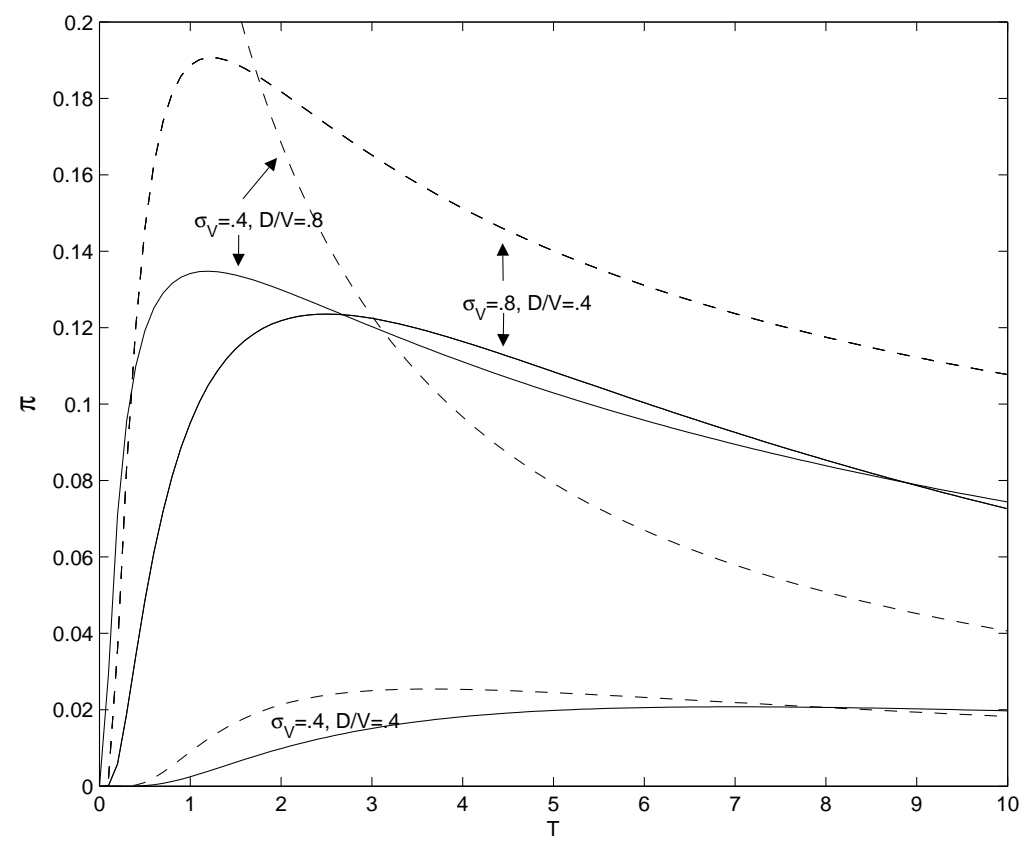

Figure 8: Estimated default probabilities as a function of time to debt maturity for different levels of asset volatility $\sigma_{V}$ and leverage $D / V$.

The solid and dashed lines are probabilities of default estimated based on model implied credit spreads $\left(\pi_{M I C S}\right)$ and the Merton distance to default model $\left(\pi_{D D}\right)$, respectively. The graph is cut-off at $\pi=.2$ for displaying purposes.

$\left(V=100, r=.05, \mu_{D D}=\mathrm{r}+.06, \delta_{E}=0, \mathrm{LGD}=.75\right)$. 


\section{List of Tables}

1 Descriptive sample statistics . . . . . . . . . . . . . . . . . . 47

2 Failures and bankruptcies per $\pi$ decile . . . . . . . . . . . . 48

$3 \quad$ Estimates of logit regressions of bankruptcy on $\pi_{M I C S}, \pi_{D D-B}$ and $\pi_{D D} . \quad 49$

4 Estimates of logit regressions of failure on $\pi_{M I C S}, \pi_{D D-B}$ and $\pi_{D D} \ldots . .50$ 
Table 1: Descriptive sample statistics.

This table displays descriptive statistics for the following variables: TLMTA, NIMTA, and CASHMTA are measured as the ratios of total liabilities, net income, as well as cash and short term assets to the market value of total assets (equal to the sum of the market value of equity and the book value of liabilities), respectively. Relative firm size RSIZE is defined as the logarithm of the market value of a firm's equity relative to the market capitalization of the S\&P500, MB as the market-to-book ratio, PRICE as the logarithm of the stock price winsorized at $\$ 15$, EXRET as a stock's excess returns over the S\&P500 during the last month, and SIGMA as the standard deviation of daily stock returns over the last three months. All variables except for PRICE are winsorized at their $5^{\text {th }}$ and $95^{\text {th }}$ percentile. Panel $1(\mathrm{a})$ contains statistics for the aggregate sample of 1,625,169 firm-months. Panel 1(b) and Panel 1(c) show statistics subsamples only containing bankruptcy and failure firm-months.

(a) All observations

\begin{tabular}{lrrrrr}
\hline & Median & Mean & \multicolumn{2}{c}{ Quartiles } & STD \\
\cline { 5 - 6 } & & & \multicolumn{1}{c}{ First } & \multicolumn{1}{c}{ Third } & \\
\hline NIMTA & 0.004 & -0.002 & -0.006 & 0.012 & 0.023 \\
CASHMTA & 0.045 & 0.084 & 0.015 & 0.118 & 0.096 \\
RSIZE & -10.749 & -10.591 & -12.069 & -9.272 & 1.887 \\
MB & 1.615 & 2.027 & 1.049 & 2.591 & 1.344 \\
PRICE & 2.442 & 1.995 & 1.447 & 2.708 & 0.891 \\
EXRET & -0.010 & -0.012 & -0.082 & 0.059 & 0.117 \\
TLMTA & 0.396 & 0.426 & 0.175 & 0.655 & 0.279 \\
SIGMA & 0.479 & 0.563 & 0.311 & 0.739 & 0.324 \\
Observations & & & & & $1,625,169$ \\
\hline
\end{tabular}

(b) Bankruptcies

\begin{tabular}{lrrrrr}
\hline & Median & Mean & \multicolumn{2}{c}{ Quartiles } & STD \\
\cline { 4 - 5 } & & & \multicolumn{1}{c}{ First } & \multicolumn{1}{c}{ Third } & \\
\hline NIMTA & -0.066 & -0.045 & -0.066 & -0.026 & 0.027 \\
CASHMTA & 0.024 & 0.052 & 0.009 & 0.061 & 0.072 \\
RSIZE & -13.107 & -12.627 & -13.498 & -12.060 & 1.107 \\
MB & 2.066 & 2.793 & 0.695 & 5.449 & 2.085 \\
PRICE & 0.000 & 0.450 & 0.000 & 0.724 & 0.655 \\
EXRET & -0.198 & -0.121 & -0.238 & -0.027 & 0.147 \\
TLMTA & 0.872 & 0.773 & 0.707 & 0.913 & 0.202 \\
SIGMA & 1.292 & 1.106 & 0.953 & 1.292 & 0.274 \\
\cline { 1 - 1 } Observations & & & & & 959 \\
\hline
\end{tabular}

(c) Failures

\begin{tabular}{lrrrrr}
\hline & Median & Mean & \multicolumn{2}{c}{ Quartiles } & STD \\
\cline { 4 - 5 } & & & \multicolumn{1}{c}{ First } & \multicolumn{1}{c}{ Third } & \\
\hline NIMTA & -0.066 & -0.044 & -0.066 & -0.023 & 0.028 \\
CASHMTA & 0.031 & 0.072 & 0.010 & 0.086 & 0.097 \\
RSIZE & -13.498 & -12.875 & -13.498 & -12.538 & 1.026 \\
MB & 1.505 & 2.434 & 0.567 & 5.285 & 2.025 \\
PRICE & 0.000 & 0.313 & 0.000 & 0.405 & 0.586 \\
EXRET & -0.189 & -0.116 & -0.238 & -0.023 & 0.150 \\
TLMTA & 0.814 & 0.712 & 0.585 & 0.913 & 0.243 \\
SIGMA & 1.292 & 1.147 & 1.083 & 1.292 & 0.249 \\
\cline { 1 - 1 } Observations & & & & & 1,647 \\
\hline
\end{tabular}


Table 2: Failures and Bankruptcy per $\pi$-Decile.

This table assesses the ability of different default measures to forecast failure and bankruptcy. Firmmonth observations are sorted according to their $\pi$-value. The reported numbers are the percentages of all 959 (912) bankruptcies (Panel 2(a)) and 1,647 (1,558) failures (Panel 2(b)) observed for the aggregate sample "All" (the sample excluding financial services firms "Non-FS") over the subsequent period.

(a) Percentage of bankruptcy filings per $\pi$-Decile

\begin{tabular}{|c|c|c|c|c|c|c|}
\hline \multirow[b]{2}{*}{ Decile } & \multicolumn{2}{|l|}{$\pi_{M I C S}$} & \multicolumn{2}{|l|}{$\pi_{D D-B}$} & \multicolumn{2}{|l|}{$\pi_{D D}$} \\
\hline & All & Non-FS & All & Non-FS & All & Non-FS \\
\hline $\begin{array}{l}1 \\
2 \\
3 \\
4 \\
5 \\
6-10\end{array}$ & $\begin{array}{l}0.763 \\
0.100 \\
0.050 \\
0.021 \\
0.008 \\
0.057\end{array}$ & $\begin{array}{l}0.747 \\
0.105 \\
0.057 \\
0.021 \\
0.010 \\
0.060\end{array}$ & $\begin{array}{l}0.731 \\
0.118 \\
0.053 \\
0.027 \\
0.012 \\
0.059\end{array}$ & $\begin{array}{l}0.715 \\
0.124 \\
0.059 \\
0.027 \\
0.012 \\
0.063\end{array}$ & $\begin{array}{l}0.717 \\
0.119 \\
0.062 \\
0.026 \\
0.014 \\
0.063\end{array}$ & $\begin{array}{l}0.697 \\
0.132 \\
0.055 \\
0.036 \\
0.014 \\
0.025\end{array}$ \\
\hline
\end{tabular}

(b) Percentage of failures per $\pi$-Decile

\begin{tabular}{|c|c|c|c|c|c|c|}
\hline \multirow[b]{2}{*}{ Decile } & \multicolumn{2}{|l|}{$\pi_{M I C S}$} & \multicolumn{2}{|l|}{$\pi_{D D-B}$} & \multicolumn{2}{|l|}{$\pi_{D D}$} \\
\hline & All & Non-FS & All & Non-FS & All & Non-FS \\
\hline 1 & 0.741 & 0.725 & 0.729 & 0.712 & 0.713 & 0.695 \\
\hline 2 & 0.095 & 0.107 & 0.103 & 0.112 & 0.106 & 0.119 \\
\hline 3 & 0.044 & 0.048 & 0.044 & 0.049 & 0.051 & 0.050 \\
\hline 4 & 0.018 & 0.019 & 0.023 & 0.022 & 0.021 & 0.026 \\
\hline & 0.009 & 0.010 & 0.010 & 0.014 & 0.013 & 0.015 \\
\hline $6-10$ & 0.092 & 0.092 & 0.092 & 0.091 & 0.095 & 0.020 \\
\hline
\end{tabular}


Table 3: Estimates of logit regressions of bankruptcy on $\pi_{M I C S}, \pi_{D D-B}, \pi_{D D}$.

This table displays the results of logit regressions of a bankruptcy indicator on $\pi_{M I C S}, \pi_{D D-B}, \pi_{D D}$ and the following control variables. TLMTA, NIMTA, and CASHMTA are measured as the ratios of total liabilities, net income, as well as cash and short term assets to the market value of total assets (equal to the sum of the market value of equity and the book value of liabilities), respectively. Relative firm size RSIZE is defined as the logarithm of the market value of a firm's equity relative to the market capitalization of the S\&P500, MB as the market-to-book ratio, PRICE as the logarithm of the stock price winsorized at $\$ 15$, EXRET as a stock's excess returns over the S\&P500 during the last month, and SIGMA as the standard deviation of daily stock returns over the last three months. All variables except for PRICE are winsorized at their $5^{t h}$ and $95^{t h}$ percentile.

\begin{tabular}{|c|c|c|c|c|c|c|c|}
\hline & (1) & $(2)$ & (3) & (4) & (5) & (6) & (7) \\
\hline (Intercept) & $\begin{array}{c}-9.346^{a} \\
(0.077)\end{array}$ & $\begin{array}{c}-8.316^{a} \\
(0.05)\end{array}$ & $\begin{array}{c}-9.388^{a} \\
(0.084)\end{array}$ & $\begin{array}{c}-9.122^{a} \\
(1.339)\end{array}$ & $\begin{array}{c}-8.081^{a} \\
(1.33)\end{array}$ & $\begin{array}{c}-8.949^{a} \\
(1.343)\end{array}$ & $\begin{array}{r}-13.929^{a} \\
(1.414)\end{array}$ \\
\hline$\pi_{M I C S}$ & $\begin{array}{l}29.592^{a} \\
(0.597)\end{array}$ & & $\begin{array}{l}30.972^{a} \\
(1.166)\end{array}$ & $\begin{array}{l}19.534^{a} \\
(1.904)\end{array}$ & & $\begin{array}{l}16.400^{a} \\
(3.238)\end{array}$ & \\
\hline$\pi_{D D-B}$ & & $\begin{array}{l}20.638^{a} \\
(0.379)\end{array}$ & $\begin{array}{c}-1.180 \\
(0.854)\end{array}$ & & $\begin{array}{l}11.470^{a} \\
(1.12)\end{array}$ & $\begin{array}{c}2.415 \\
(2.034)\end{array}$ & \\
\hline NIMTA & & & & $\begin{array}{c}-28.508^{a} \\
(3.418)\end{array}$ & $\begin{array}{c}-30.015^{a} \\
(3.488)\end{array}$ & $\begin{array}{r}-28.565^{a} \\
(3.428)\end{array}$ & $\begin{array}{r}-28.071^{a} \\
(3.463)\end{array}$ \\
\hline CASHMTA & & & & $\begin{array}{c}-3.111^{a} \\
(1.031)\end{array}$ & $\begin{array}{c}-3.800^{a} \\
(1.026)\end{array}$ & $\begin{array}{c}-3.132^{a} \\
(1.031)\end{array}$ & $\begin{array}{c}-2.232^{b} \\
(1.049)\end{array}$ \\
\hline RSIZE & & & & $\begin{array}{c}-0.040 \\
(0.098)\end{array}$ & $\begin{array}{c}-0.043 \\
(0.099)\end{array}$ & $\begin{array}{c}-0.035 \\
(0.098)\end{array}$ & $\begin{array}{r}-0.061 \\
(0.095)\end{array}$ \\
\hline MB & & & & $\begin{array}{l}0.195^{a} \\
(0.04)\end{array}$ & $\begin{array}{c}0.195^{a} \\
(0.041)\end{array}$ & $\begin{array}{c}0.197^{a} \\
(0.041)\end{array}$ & $\begin{array}{c}0.228^{a} \\
(0.039)\end{array}$ \\
\hline PRICE & & & & $\begin{array}{c}-0.564^{a} \\
(0.176)\end{array}$ & $\begin{array}{c}-0.741^{a} \\
(0.173)\end{array}$ & $\begin{array}{c}-0.569^{a} \\
(0.176)\end{array}$ & $\begin{array}{c}-0.359^{b} \\
(0.182)\end{array}$ \\
\hline EXRET & & & & $\begin{array}{c}-1.406^{a} \\
(0.519)\end{array}$ & $\begin{array}{c}-1.563^{a} \\
(0.527)\end{array}$ & $\begin{array}{c}-1.426^{a} \\
(0.519)\end{array}$ & $\begin{array}{c}-0.973^{c} \\
(0.52)\end{array}$ \\
\hline TLMTA & & & & & & & $\begin{array}{c}5.168^{a} \\
(0.446)\end{array}$ \\
\hline SIGMA & & & & & & & $\begin{array}{c}2.769^{a} \\
(0.426)\end{array}$ \\
\hline Pseudo $R^{2}$ & 0.186 & 0.143 & 0.186 & 0.309 & 0.300 & 0.309 & 0.320 \\
\hline
\end{tabular}

$\overline{a, b}$, and $c$ indicate significance at the $1 \%, 5 \%$, and $10 \%$ Level, respectively. Standard errors are reported in parentheses. 
Table 4: Estimates of logit regressions of failure on $\pi_{M I C S}, \pi_{D D-B}, \pi_{D D}$.

This table displays the results of logit regressions of a failure indicator on $\pi_{M I C S}, \pi_{D D-B}, \pi_{D D}$ and the following control variables. TLMTA, NIMTA, and CASHMTA are measured as the ratios of total liabilities, net income, as well as cash and short term assets to the market value of total assets (equal to the sum of the market value of equity and the book value of liabilities), respectively. Relative firm size RSIZE is defined as the logarithm of the market value of a firm's equity relative to the market capitalization of the S\&P500, MB as the market-to-book ratio, PRICE as the logarithm of the stock price winsorized at $\$ 15$, EXRET as a stock's excess returns over the S\&P500 during the last month, and SIGMA as the standard deviation of daily stock returns over the last three months. All variables except for PRICE are winsorized at their $5^{t h}$ and $95^{t h}$ percentile.

\begin{tabular}{|c|c|c|c|c|c|c|c|}
\hline & (1) & $(2)$ & (3) & (4) & (5) & (6) & (7) \\
\hline (Intercept) & $\begin{array}{c}-8.714^{a} \\
(0.057)\end{array}$ & $\begin{array}{c}-7.780^{a} \\
(0.038)\end{array}$ & $\begin{array}{c}-8.679^{a} \\
(0.06)\end{array}$ & $\begin{array}{c}-9.679^{a} \\
(1.151)\end{array}$ & $\begin{array}{c}-8.849^{a} \\
(1.147)^{a}\end{array}$ & $\begin{array}{c}-9.323^{a} \\
(1.152)\end{array}$ & $\begin{array}{r}-13.270^{a} \\
(1.185)\end{array}$ \\
\hline$\pi_{M I C S}$ & $\begin{array}{l}28.837^{a} \\
(0.447)\end{array}$ & & $\begin{array}{l}27.584^{a} \\
(0.885)\end{array}$ & $\begin{array}{l}15.066^{a} \\
(1.306)\end{array}$ & & $\begin{array}{c}9.161^{a} \\
(2.351)\end{array}$ & \\
\hline$\pi_{D D-B}$ & & $\begin{array}{c}20.733^{a} \\
(0.29)\end{array}$ & $\begin{array}{c}1.081 \\
(0.661)\end{array}$ & & $\begin{array}{l}10.033^{a} \\
(0.819)\end{array}$ & $\begin{array}{c}4.662^{a} \\
(1.567)\end{array}$ & \\
\hline NIMTA & & & & $\begin{array}{c}-23.652^{a} \\
(2.411)\end{array}$ & $\begin{array}{c}-24.241^{a} \\
(2.431)\end{array}$ & $\begin{array}{r}-23.694^{a} \\
(2.418)\end{array}$ & $\begin{array}{r}-22.345^{a} \\
(2.413)\end{array}$ \\
\hline CASHMTA & & & & $\begin{array}{c}-1.066^{c} \\
(0.643)\end{array}$ & $\begin{array}{c}-1.521^{b} \\
(0.637)\end{array}$ & $\begin{array}{c}-1.113^{c} \\
(0.644)\end{array}$ & $\begin{array}{r}-0.626 \\
(0.651)\end{array}$ \\
\hline RSIZE & & & & $\begin{array}{c}-0.201^{b} \\
(0.085)\end{array}$ & $\begin{array}{c}-0.191^{b} \\
(0.085)\end{array}$ & $\begin{array}{c}-0.189^{b} \\
(0.085)\end{array}$ & $\begin{array}{c}-0.162^{b} \\
(0.083)\end{array}$ \\
\hline MB & & & & $\begin{array}{c}0.143^{a} \\
(0.033)\end{array}$ & $\begin{array}{c}0.143^{a} \\
(0.033)\end{array}$ & $\begin{array}{c}0.146^{a} \\
(0.033)\end{array}$ & $\begin{array}{c}0.174^{a} \\
(0.032)\end{array}$ \\
\hline PRICE & & & & $\begin{array}{c}-0.984^{a} \\
(0.147)\end{array}$ & $\begin{array}{c}-1.076^{a} \\
(0.145)\end{array}$ & $\begin{array}{c}-0.992^{a} \\
(0.147)\end{array}$ & $\begin{array}{r}-0.718^{a} \\
(0.152)\end{array}$ \\
\hline EXRET & & & & $\begin{array}{c}-1.294^{a} \\
(0.395)\end{array}$ & $\begin{array}{c}-1.424^{a} \\
(0.399)\end{array}$ & $\begin{array}{c}-1.332^{a} \\
(0.396)\end{array}$ & $\begin{array}{c}-0.959^{b} \\
(0.391)\end{array}$ \\
\hline TLMTA & & & & & & & $\begin{array}{c}3.442^{a} \\
(0.269)\end{array}$ \\
\hline SIGMA & & & & & & & $\begin{array}{c}3.075^{a} \\
(0.343)\end{array}$ \\
\hline Pseudo $R^{2}$ & 0.190 & 0.155 & 0.190 & 0.316 & 0.315 & 0.318 & 0.317 \\
\hline
\end{tabular}

$\overline{a, b}$, and $c$ indicate significance at the $1 \%, 5 \%$, and 10\% Level, respectively. Standard errors are reported in parentheses. 